\title{
A atividade de extensão na terapia ocupacional: revisáo de escopo na literatura nacional
}

\section{University outreach in occupational therapy: scoping review in Brazilian literature}

\author{
Mirela de Oliveira Figueiredo ${ }^{a}$ (D), Renata Batistão ${ }^{a}$ (D), Carla Regina Silva ${ }^{a}$ (D), \\ Claudia Maria Simóes Martinez ${ }^{a}$ (D), Roberta Giampá Roiz ${ }^{a}$ (D) \\ ${ }^{a}$ Universidade Federal de São Carlos - UFSCar, São Carlos, SP, Brasil.
}

Como citar: Figueiredo, M. O., Batistão, R., Silva, C. R., Martinez, C. M. S., \& Roiz, R. G. (2022). A atividade de extensão na terapia ocupacional: revisão de escopo na literatura nacional. Cadernos Brasileiros de Terapia Ocupacional, 30, e2908. https://doi.org/10.1590/2526-8910.ctoAR21972908

\begin{abstract}
$\underline{\text { Resumo }}$
Introdução: A extensão universitária possibilita a inter-relação entre a universidade e a sociedade, além da democratização do conhecimento acadêmico. Objetivo: Analisar e caracterizar a literatura nacional referente à extensão universitária da terapia ocupacional brasileira. Método: Revisão de escopo nos periódicos: Cadernos Brasileiros de Terapia Ocupacional, Revista de Terapia Ocupacional da USP e Revista Baiana de Terapia Ocupacional. Foram utilizadas as palavras-chaves "extensão universitária", "atividade de extensão", "atividade extensionista" e "extensão". Realizou-se a análise dos dados quantitativos por meio de estatística simples de frequência e média e dos qualitativos por categorização temática. Resultados: A amostra foi composta por 43 publicaçóes, sendo 25 artigos originais, 17 relatos de experiência e 1 editorial publicados entre 2003 e 2020. As publicaçóes abordavam sobre atividade, projeto e/ou programa de extensão, sendo diversos os objetivos, participantes, locais e açôes concretizadas. Alguns estudos, além de descrever as atividades de extensão, apresentaram temas reincidentes que propiciaram a criação de quatro categorias temáticas: "indissociabilidade entre ensino e pesquisa", "relação da universidade com a comunidade", "processo de ensino-aprendizagem" e "formação discente". Conclusão: Verificou-se que a extensão universitária realizada pelos docentes dos cursos de graduaçáo em terapia ocupacional no Brasil foi realizada de forma integrada com o ensino e a pesquisa. A extensão universitária tem favorecido a relação entre a sociedade e a universidade, uma vez que os projetos/atividades têm respondido às demandas sociais e favorecido à democratização do saber acadêmico. Tais projetos/atividade têm impactado
\end{abstract}


positivamente no processo de ensino e aprendizagem dos graduandos em terapia ocupacional no Brasil, pois propiciam uma formação crítica e reflexiva.

Palavras-chave: Relaçôes Comunidade-Instituição, Produção Científica e Tecnológica, Terapia Ocupacional, Ensino Superior.

\section{$\underline{\text { Abstract }}$}

Introduction: The university outreach allows the interrelation between the university and society and the democratization of academic knowledge. Objective: To analyze and characterize the national literature regarding the university outreach of Brazilian Occupational Therapy. Method: Scope review in the Brazilian Journal of Occupational Therapy, Revista de Terapia Ocupacional USP and Revista Baiana de Terapia Ocupacional. The keywords "university extension", "extension activity", "extensionist activity" and "extension" were used. Analysis of quantitative data using simple statistics of frequency and average and qualitative data by thematic categorization. Results: The sample consisted of 43 publications, with 25 original articles, 17 experience reports, and 1 Editorial published between 2003 and 2020. The publications addressed an activity, project, and/or university outreach program with different objectives, participants, locations, and actions implemented. Some studies, in addition to describing the university outreach activities, presented recurrent themes that led to the creation of four thematic categories "Inseparability between teaching and research"; "University's relationship with the community", "Teaching-learning process" and "Student training". Conclusion: It was found that the University outreach carried out by professors of Occupational Therapy courses in Brazil were carried out in an integrated manner with teaching and research. This university outreach has favored the relationship between society and the university since the projects/activities have responded to social demands and favored the democratization of academic knowledge. Such projects/activities have had a positive impact on the teaching and learning process of undergraduate students in Occupational Therapy in Brazil because they provide critical and reflective training.

Keywords: Community-Institutional Relations, Scientific and Technical Activities, Occupational Therapy, Education, Higher.

\section{Introduçáo}

\section{A extensão universitária em disputa}

As primeiras experiências extensionistas no Brasil ocorreram entre 1911 e 1917, na Universidade Livre de São Paulo, com conferências e semanas abertas ao público, sem que problemas sociais ou econômicos estivessem pautados. Em 1931, o "Estatuto da Universidade Brasileira" já definia a extensão como atividades que apresentassem soluçóes para os compromissos sociais de interesse nacional. A década de 1950 e o início da década seguinte foram marcados pela mobilização popular e reformas sociais; nesse momento, as atividades de extensão passaram do enfoque de difusáo de conhecimento para a busca de respostas para a realidade 
socioeconômica, política e cultural do país (Freire, 1977; Carbonari \& Pereira, 2007).

Contudo, com o golpe civil e militar de 1964 e a promulgação da Reforma Universitária (Lei 5.540/68), foram restritas as açóes das Instituiçóes de Ensino Superior e sua autonomia e foi estabelecida a indissociabilidade entre ensino e pesquisa, impactando diretamente na concepção da extensão, rompendo com qualquer caráter de diálogo com a comunidade ou como projeto de transformação social e reforçando modelo assistencialista (Nogueira, 2001; Carbonari \& Pereira, 2007; Paula, 2013).

Em 1975, o Conselho de Reitores das Universidades Brasileiras define a extensão como a prestação de serviços, realimentação da universidade e a integração de ambas. Apesar da presença indiscutível da comunidade nas atividades extensionistas, essa relação se dá de forma unilateral: "a ação extensionista não expóe as contradiçóes geradoras dos problemas enfrentados pela comunidade e desarticula sua capacidade de organização e transformação da realidade" (Carbonari \& Pereira, 2007, p. 24).

$\mathrm{Na}$ década de 1980, marcada novamente pelos movimentos sociais, a universidade compartilha e constrói com a sociedade o projeto democrático. Assim, a extensão se torna essencial para essas práticas; contudo, ela se dá com a presente disputa entre a emancipação e o assistencialismo (Carbonari \& Pereira, 2007).

$\mathrm{Na}$ última década do século passado, é retomada a indissociabilidade entre ensino, pesquisa e extensão. A extensão universitária foi inserida como uma das funçóes da universidade, com o objetivo de difundir para a sociedade os conhecimentos e as informaçôes resultantes de pesquisa científica, tecnológica e/ou produção cultural produzidos na instituição, promovendo a universalização e o aprimoramento da educação básica e a formação e a capacitação de profissionais, aproximando os dois níveis escolares (Brasil, 1996).

A extensão universitária acompanhou as mudanças paradigmáticas ocorridas tanto nos entendimentos sobre sua função educacional quanto naquelas que aconteceram com a própria sociedade (Fórum de Pró-Reitores de Extensão das Universidades Públicas Brasileiras, 2006). As suas funções, ações, alcances e objetivos podem ser diversificados e dependem dos processos sócio-históricos de cada região, assim como da autonomia universitária perante as agendas políticas das instâncias de gestão e poder às quais está vinculada.

Da mesma forma, os consensos sobre as atividades, funçôes e objetivos devem estar apoiados em pilares sólidos democráticos e éticos para, acima de tudo, responder ao compromisso social e de enfrentamento aos processos de exclusóes e desigualdades sociais, em comunhão com a função social da própria universidade pública, laica, gratuita, de qualidade e para todos. Contudo, os debates ideológicos, discursivos e políticos sobre a extensão universitária respondem a diferentes e contraditórios polos argumentativos e decisivos.

Ainda assim, ao longo dos anos, podemos perceber que a extensão universitária se transformou em um instrumento de inter-relação da universidade com a sociedade, de oxigenação da própria universidade e de democratização do conhecimento acadêmico por meio da troca de saberes com as comunidades. Desta forma, representa-se uma via de mão dupla que pode oferecer múltiplas 
possibilidades de transformação da sociedade e da própria universidade (Fórum de Pró-Reitores de Extensão das Universidades Públicas Brasileiras, 2012).

Esta troca de saberes sistematizados, acadêmicos e populares tem como consequências a produção do conhecimento resultante do confronto com a realidade brasileira e regional, a democratização do conhecimento acadêmico e a participação efetiva da comunidade na atuação da universidade. Além de proporcionar este processo dialético entre teoria e prática, a extensão pode ser considerada como parte de um trabalho interdisciplinar que favorece a visão integrada sobre as necessidades da sociedade com capacidade de buscar respostas para elas (Fórum de Pró-Reitores de Extensão das Universidades Públicas Brasileiras, 2006).

$\mathrm{Na}$ atualidade, entende-se que a extensão universitária pode contribuir na formulação e no desenvolvimento de políticas através de sua ação e reflexão tanto no âmbito acadêmico como nos espaços sociais, conforme articula ensino e pesquisa, favorecendo a interação e o diálogo com diferentes setores da sociedade civil e cumprindo com o compromisso social da Universidade, prioritariamente pública (Fórum de Pró-Reitores de Extensão das Universidades Públicas Brasileiras, 2012).

As atividades de extensão são consideradas aquelas que diretamente envolvem as comunidades externas às instituiçóes de ensino superior (IES) e que estejam vinculadas à formação do estudante em conformidade com normas institucionais próprias de cada IES. Além disso, as atividades extensionistas, em consonância com os projetos políticos pedagógicos de cada curso, inserem-se nas seguintes modalidades: programas, projetos, cursos e oficinas, eventos e/ou prestação de serviços. Segundo as atuais diretrizes para a extensão na educação superior brasileira, as atividades de extensão deverão fazer parte da matriz curricular dos cursos de graduaçáo, compondo no mínimo $10 \%$ do total da carga horária curricular (Brasil, 2018).

Assim, ressaltamos a concepção da extensão universitária como um agente formador de um profissional cidadão que integra saberes e fazeres da universidade e da comunidade, transformando-se em um instrumento de mudança nas instituiçôes onde se desenvolve e principalmente na sociedade em que se aplica.

É preciso concebê-las como estratégias alternativas "ao capitalismo global, atribuindo às universidades uma participação ativa na construção da coesão social, no aprofundamento da democracia, na luta contra a exclusão social e a degradação ambiental, na defesa da diversidade cultural" (Santos \& Filho, 2008, p. 66-67).

\section{A extensáo universitária e a formaçáo em terapia ocupacional}

A terapia ocupacional é reconhecida por suas práticas plurais traduzidas em atendimentos, processos de cuidados, oficinas, grupos realizados individualmente ou coletivamente, em serviços, espaços públicos, privados ou do terceiro setor, em âmbito hospitalar, clínico, comunitário ou territorial, voltada para pessoas, grupos e comunidades em todos os cursos de vida.

Sabe-se que os cursos de graduação em terapia ocupacional no Brasil têm realizado atividades extensionistas, pois o próprio ensino em terapia ocupacional 
requer conhecimentos teóricos e práticos, envolvendo não apenas o docente e o aluno, como também toda comunidade, denominada muitas vezes como sujeitos da intervenção terapêutica ocupacional, pacientes, usuários, clientes, participantes, pessoas, grupos e/ou outros coletivos e comunidades.

Assim, as atividades de extensão voltadas ao atendimento da comunidade se tornaram uma prática recorrente nos cursos, pois favorecem o ensino por meio da prática e de suas respectivas teorias. Por exemplo, têm-se o registro de que, nos últimos 17 anos, os docentes do curso de terapia ocupacional da UFSCar concretizaram 425 atividades de extensão (Figueiredo et al., 2020).

Nascimento \& Souza (2017) contabilizam no ano de 2012 que o Instituto de Ciências da Saúde (ICS) da Universidade Federal do Pará (UFPA) foi contemplado com 77 bolsas de extensão. Considerando o quantitativo de 2.573 alunos matriculados por curso no ICS, os bolsistas representaram: 1\% dos alunos de odontologia, $1 \%$ de fisioterapia, $2 \%$ de enfermagem, $2 \%$ de farmácia, $3 \%$ de medicina e $5 \%$ de terapia ocupacional. Esta porcentagem de bolsas para alunos da terapia ocupacional estava relacionada a 80 projetos de extensão em atividade no período da contabilização.

Uma vez que o ensino em terapia ocupacional ocorre por meio das fundamentaçôes teóricas e da prática, a própria prática e a relação direta com pessoas, grupos e comunidades repercute em reflexóes e questionamentos sobre os conteúdos teóricos. À medida que se intervém nas reais necessidades destes grupos, descobre-se novas formas de se pensar e fazer saúde, educação e assistência social. Com isso, gera-se a necessidade de produção de novos conhecimentos e pressupostos teóricos (Emmel, 2010).

Assim, docentes dos cursos de terapia ocupacional têm produzido conhecimento na integração entre os pilares da universidade, sendo ensino, pesquisa e extensão. A pesquisa constitui, nessa perspectiva, uma ferramenta indispensável para a geração de novas hipóteses, enraizadas e fundamentadas na vida e nas reais necessidades da população. As atividades formativas proporcionadas pelo ensino e por meio da extensáo são geradoras de novos questionamentos e interpelações; logo, são indutoras de novas hipóteses e práticas sociais proativas (Pivetta et al., 2010). Esta articulação tem ocorrido nas situações em que docente e discente estáo em campo, com o objetivo de concretização do processo de ensino aprendizagem teórico-prático, o que, por um lado, fornece a assistência às demandas dos sujeitos envolvidos e participantes das práticas e, por outro, reformula e constrói dados acerca da eficácia, relevância e consequência das ações empregadas, confirmando, refutando ou modificando as fundamentaçóes teóricas (Emmel, 2010).

Nesse sentido, as atividades de extensão têm promovido o acesso, a permanência e a qualificação dos serviços públicos, ampliando as açóes oferecidas por esses espaços. Também têm auxiliado na formação continuada de profissionais, desenvolvendo o atendimento à comunidade por meio da integração entre ensino, pesquisa e extensão universitária. Além disso, têm contribuído para a divulgação e ampliação das possibilidades de atuação da terapia ocupacional junto às comunidades (Figueiredo et al., 2020, p. 23). 
Apesar da prática extensionista estar presente nos cursos de terapia ocupacional no Brasil, mediante uma revisão de literatura inicial sobre esta temática, não foram encontrados estudos que sistematizassem a forma como a extensão universitária tem sido realizada e qual a produção científica gerada a partir delas. Considerando a importância de se conhecer qual o papel da extensão na formação discente e docente, a sua articulação com o ensino e a pesquisa e os possíveis fatores vinculados a uma prática bem-sucedida de extensão universitária, objetivou-se com este estudo analisar a produção científica na literatura nacional referente às atividades de extensão no campo da terapia ocupacional.

\section{Metodologia}

Trata-se de um estudo de revisão de escopo, que teve como propósito mapear publicaçóes de terapeutas ocupacionais vinculados à universidade e atividades extensionistas, buscando subsidiar o debate sobre a importância da extensão universitária para a formação em terapia ocupacional.

A revisão de escopo deve identificar os conceitos e as lacunas existentes numa determinada área do saber, preferencialmente destinada às áreas que não tenham sido revisadas anteriormente (Arksey \& O’Malley, 2005), como é o caso do presente estudo.

Foram adotados os parâmetros indicados por Arksey \& O’Malley (2005) e replicados por O’Brien et al. (2016), Peters et al. (2015), Colquhoun et al. (2014) e Tricco et al. (2016). Com isso, o presente estudo foi realizado em cinco etapas, a saber:

1. estabelecimento das perguntas de pesquisa;

2. busca dos estudos por meio de diferentes fontes;

3. composição da amostra com base em critérios de busca e inclusão/exclusão;

4. coleta das informaçóes relativas à pergunta de pesquisa;

5. descrição dos resultados obtidos por meio de análise numérica e temática/conceitual com respectiva discussão.

As perguntas de pesquisa que conduziram este estudo foram:

Quais foram os objetivos das atividades de extensão da terapia ocupacional brasileira?

Quais pessoas, grupos e comunidades foram participantes e protagonistas destas atividades de extensão?

Onde as atividades de extensão foram realizadas, qual foi o tempo de duração e quais eram os membros da equipe?

Os artigos referiam sobre a relação indissociável entre a extensão, o ensino e a pesquisa?

Os artigos referiam sobre a atividade de extensão favorecer a relação entre universidade e comunidade?

Os artigos referiam sobre o papel da extensão no processo de ensino-aprendizagem teórico e prático?

Os artigos referiam sobre o impacto da extensão na formação discente e docente?

\section{Procedimentos de coleta e análise dos dados}

Foram analisados três periódicos nacionais da área de terapia ocupacional: os Cadernos Brasileiros de Terapia Ocupacional da UFSCar, a Revista de Terapia 
Ocupacional da Universidade de São Paulo e a Revista Baiana de Terapia Ocupacional. Para a busca dos artigos, foram utilizadas as palavras-chaves "extensão universitária", "atividade de extensão", "atividade extensionista" e "extensão".

Como critério para inclusão e composição da amostra, foram consideradas publicaçóes disponíveis online nos periódicos, independente dos objetivos, população ou metodologia do estudo, publicadas de 1990 a 2020 e tendo sido elaboradas por terapeutas ocupacionais enquanto artigo cientifico ou relato de experiência sobre o tema Terapia Ocupacional e Extensão Universitária.

Este período se justifica pela disponibilidade online desses materiais em seus sites: o Cadernos Brasileiros de Terapia Ocupacional da UFSCar inicia em 1990, a Revista de Terapia Ocupacional da USP a partir de 2002 e a Revista Bahiana de Terapia Ocupacional possui alguns volumes em 2004, 2005, 2007, 2012 e 2013.

Nesta direção, foram excluídas as publicaçôes que, apesar de apareceram na busca, não continham os descritores no texto ou que, mesmo contendo os descritores, não foram produzidos por terapeutas ocupacionais e/ou não se tratavam de projetos/atividades de extensão realizadas e reportadas por terapeutas ocupacionais.

Foi utilizado um formulário para registro das informaçóes, composto pelos itens título, autor, ano de publicação, tipo de publicação, objetivos das atividades de extensão, público alvo, locais onde foram realizadas, duração e membros da equipe.

Foram identificadas 363 publicaçóes na Revista de Terapia Ocupacional da USP, 101 nos Cadernos Brasileiros de Terapia Ocupacional da UFSCar e 1 na Revista Baiana de Terapia Ocupacional. A Figura 1 ilustra o quantitativo de artigos encontrados por palavra-chave em cada periódico e os excluídos por estarem em duplicidade e por não corresponderem aos critérios de inclusão. Após a retirada dos artigos duplicados, foi feita a leitura dos artigos na íntegra e, conforme os critérios de inclusão/exclusão, a amostra ficou constituída por 43 publicaçóes, sendo 21 dos Cadernos Brasileiros de Terapia Ocupacional da UFSCar somados com 22 da Revista de Terapia Ocupacional da USP.

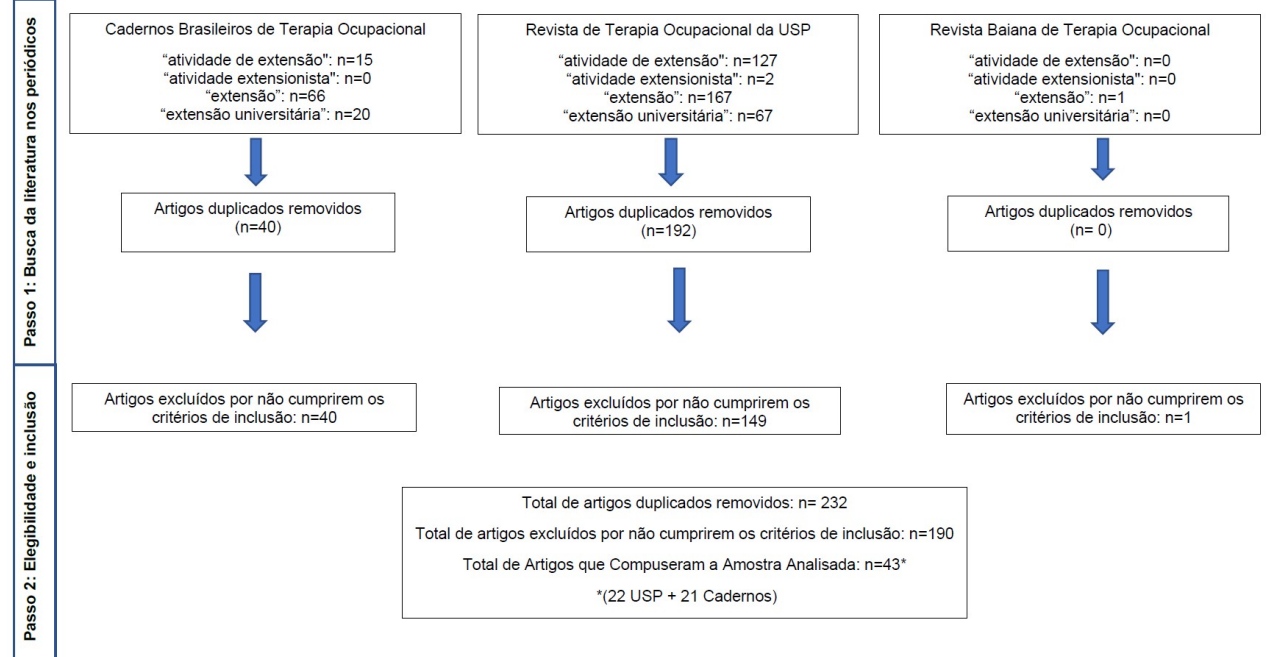

Figura 1. Fluxograma de Composição da Amostra. 
Adotou-se o método misto de análise dos dados (DePoy \& Gitlin, 2011) e foi feita a análise quantitativa por meio do somatório das publicações encontradas e realização da estatística simples de frequência, apresentando os resultados em forma de gráficos e quadros. Também se fez a análise qualitativa dos temas que apareceram de forma repetida nas publicaçóes, sendo estes categorizados por similaridade temática que são descritas e discutidas conforme interpretação e inferência.

\section{Resultados}

Em relação ao ano de publicação das 43 publicaçóes recuperadas no período de 2003 a 2020, verificou-se que, com exceção do ano de 2006, houve publicações em todos os outros anos. A quantidade de publicação por ano variou, sendo que, em ordem de maior número de publicação, elencam-se: os anos de 2019 (n=9), $2016(n=6)$ e $2009(n=4)$. Em igual quantidade de publicação, citam-se: os anos de 2012, 2013, 2014 e 2018, com 3 publicaçóes; os anos de 2003 e 2005, com 2 publicaçóes; e os anos de 2004, 2007, 2008, 2010 e 2011, com 1 publicação no ano.

Dentre os tipos de publicação, foram 25 artigos originais, 17 relatos de experiência e um editorial. Estas publicaçóes abarcaram uma multiplicidade de objetivos, assim como, as atividades, projetos e programas tiveram diversos enfoques, participantes, locais de realização e equipes de trabalho. $\mathrm{Na}$ Tabela 1, são apresentadas as 43 publicaçóes, sendo especificado se elas se tratavam de artigo original ou relato de experiência, a temática abordada na publicação e uma síntese da atividade de extensão.

Tabela 1. Caracterização das publicaçôes que compuseram a amostra final.

\begin{tabular}{|c|c|c|c|c|}
\hline & Autor/ Ano & $\begin{array}{l}\text { Artigo original } \\
\text { ou Relato de } \\
\text { experiência }\end{array}$ & $\begin{array}{c}\text { Temática abordada na } \\
\text { publicaçáo }\end{array}$ & Síntese da atividade de extensáo \\
\hline 1 & $\begin{array}{c}\text { Della } \\
\text { Barba et al. } \\
(2015)\end{array}$ & $\begin{array}{c}\text { Relato de } \\
\text { experiência }\end{array}$ & $\begin{array}{l}\text { Avaliaçáo que participantes de } \\
\text { uma Atividade Curricular de } \\
\text { Integração Ensino, Pesquisa e } \\
\text { Extensão (ACIEPE) fazem sobre } \\
\text { a atividade e sobre o impacto } \\
\text { desta na formação profissional e } \\
\text { continuidade. }\end{array}$ & $\begin{array}{l}\text { ACIEPE coordenada por docente do } \\
\text { Departamento de Terapia } \\
\text { Ocupacional (DTO) da } \\
\text { Universidade Federal de São Carlos } \\
\text { (UFSCar) voltada à formaçáo de } \\
\text { educadores da rede municipal de } \\
\text { ensino infantil e graduandos do } \\
\text { curso de Terapia Ocupacional da } \\
\text { UFSCar em promoçáo do } \\
\text { desenvolvimento infantil no } \\
\text { cotidiano da família e da escola. }\end{array}$ \\
\hline 2 & $\begin{array}{c}\text { Garcia et al. } \\
\text { (2012). }\end{array}$ & Artigo original & $\begin{array}{l}\text { Opinião de profissionais da } \\
\text { enfermaria pediátrica de um } \\
\text { Hospital Universitário, } \\
\text { localizado no interior do Estado } \\
\text { de São Paulo, sobre o programa } \\
\text { de extensão Caixa de Histórias } \\
\text { realizado no contexto da } \\
\text { hospitalização infantil. }\end{array}$ & $\begin{array}{l}\text { Implementação de atividade junto às } \\
\text { crianças e adolescentes internados na } \\
\text { enfermaria pediátrica enquanto } \\
\text { estratégia para acolhimento e } \\
\text { promoção do enfrentamento da } \\
\text { hospitalizaçáo e capacitaçáo } \\
\text { profissional dos graduandos do curso } \\
\text { de Terapia Ocupacional da } \\
\text { Universidade de São Paulo (USP) } \\
\text { campus Ribeirão Preto. }\end{array}$ \\
\hline
\end{tabular}


Tabela 1. Continuação...

\begin{tabular}{|c|c|c|c|c|}
\hline & Autor/ Ano & $\begin{array}{l}\text { Artigo original } \\
\text { ou Relato de } \\
\text { experiência }\end{array}$ & $\begin{array}{c}\text { Temática abordada na } \\
\text { publicaçáo }\end{array}$ & Síntese da atividade de extensáo \\
\hline 3 & $\begin{array}{c}\text { Correia \& } \\
\text { Akerman } \\
(2015) .\end{array}$ & $\begin{array}{c}\text { Relato de } \\
\text { experiência }\end{array}$ & $\begin{array}{l}\text { Relata uma experiência } \\
\text { interdisciplinar de extensão } \\
\text { universitária voltada ao } \\
\text { desenvolvimento local participativo } \\
\text { promovido pela Faculdade de } \\
\text { Medicina do ABC, Santo André, } \\
\text { S.P., na cidade ribeirinha de } \\
\text { Araguaiana, MT. }\end{array}$ & $\begin{array}{l}\text { Prestação de assistência em saúde, social } \\
\text { e de educaçáo ambiental para uma } \\
\text { população ribeirinha. A terapia } \\
\text { ocupacional especificamente se voltava } \\
\text { para o engajamento dos indivíduos e } \\
\text { grupos nas atividades da vida cotidiana } \\
\text { com a finalidade de construir suportes } \\
\text { diários para manutenção e inventividade } \\
\text { da própria vida. }\end{array}$ \\
\hline 4 & $\begin{array}{l}\text { Lima et al. } \\
(2016) \text {. }\end{array}$ & $\begin{array}{c}\text { Relato de } \\
\text { experiência }\end{array}$ & $\begin{array}{l}\text { Apresenta o Programa de Atenção } \\
\text { Integral à Saúde do Artista de } \\
\text { Performance do Serviço } \\
\text { Especializado em Saúde do } \\
\text { Trabalhador do Hospital das } \\
\text { Clínicas da Universidade Federal de } \\
\text { Minas Gerais e relata as açóes } \\
\text { desenvolvidas pela equipe } \\
\text { interdisciplinar. }\end{array}$ & $\begin{array}{l}\text { Ações assistenciais individuais e } \\
\text { coletivas para prevenção de doenças, } \\
\text { promoção e vigilância em saúde de } \\
\text { artistas músicos. Formação } \\
\text { profissional dos estudantes } \\
\text { participantes e produção de } \\
\text { conhecimento a partir da experiência } \\
\text { extensionista. }\end{array}$ \\
\hline 5 & $\begin{array}{c}\text { Galheigo \& } \\
\text { Angeli (2008). }\end{array}$ & Artigo original & $\begin{array}{l}\text { Apresenta o Projeto } \\
\text { ACCALANTO que desenvolve } \\
\text { atividades de ensino, pesquisa, } \\
\text { extensão no âmbito da terapia } \\
\text { ocupacional e da saúde da criança e } \\
\text { do adolescente, sob a perspectiva da } \\
\text { integralidade e humanização do } \\
\text { cuidado e da proteção integral da } \\
\text { infância e da juventude. }\end{array}$ & $\begin{array}{l}\text { Acolhimento das necessidades de } \\
\text { crianças e adolescentes internados } \\
\text { em enfermaria pediátrica e de suas } \\
\text { famílias/cuidadores, ocasionadas } \\
\text { pelo processo de adoecimento e } \\
\text { hospitalização e pelas condiçôes de } \\
\text { vulnerabilidade social a que estão } \\
\text { submetidos. }\end{array}$ \\
\hline 6 & $\begin{array}{l}\text { Alves et al. } \\
\text { (2012). }\end{array}$ & Artigo original & $\begin{array}{l}\text { Descreve o perfil sócio } \\
\text { demográfico, de lesão/trauma e } \\
\text { de funcionalidade /incapacidade } \\
\text { de pessoas atendidas no projeto } \\
\text { de extensão Reabilitação de Mão } \\
\text { no Contexto da terapia } \\
\text { ocupacional destinada } \\
\text { exclusivamente à terapia da mão, } \\
\text { realizada em um centro de } \\
\text { reabilitação vinculado a um } \\
\text { hospital universitário. }\end{array}$ & $\begin{array}{l}\text { Atendimento a pacientes com lesão } \\
\text { ou trama da mão que são } \\
\text { encaminhados para reabilitação } \\
\text { terapêutico-ocupacional em um } \\
\text { centro de reabilitaçáo vinculado a } \\
\text { um hospital universitário. }\end{array}$ \\
\hline 7 & $\begin{array}{l}\text { Noordhoek et al. } \\
\text { (2009). }\end{array}$ & Artigo original & $\begin{array}{l}\text { Descreve a experiência da atuação } \\
\text { da terapia ocupacional no projeto } \\
\text { de extensáo Grupo de Orientaçáo } \\
\text { aos Indivíduos Acometidos por } \\
\text { Doenças Reumáticas, parceria } \\
\text { entre o departamento de terapia } \\
\text { ocupacional e o Serviço de } \\
\text { Reumatologia da Faculdade de } \\
\text { Medicina da Universidade Federal } \\
\text { de Minas Gerais. }\end{array}$ & $\begin{array}{l}\text { Grupo de orientação para promoçáo } \\
\text { da saúde de pessoas com doenças } \\
\text { reumáticas por meio da oferta de } \\
\text { atividades que auxiliem no } \\
\text { conhecimento sobre a doença e seus } \\
\text { impactos funcionais para auxiliar na } \\
\text { transformação do comportamento } \\
\text { dos participantes }\end{array}$ \\
\hline
\end{tabular}


Tabela 1. Continuação...

\begin{tabular}{|c|c|c|c|c|}
\hline & Autor/ Ano & $\begin{array}{l}\text { Artigo original } \\
\text { ou Relato de } \\
\text { experiência }\end{array}$ & $\begin{array}{c}\text { Temática abordada na } \\
\text { publicaçáo }\end{array}$ & Síntese da atividade de extensáo \\
\hline 8 & $\begin{array}{l}\text { Silva et al. } \\
(2018 \mathrm{a})\end{array}$ & Artigo Original & $\begin{array}{l}\text { Apresenta os resultados do } \\
\text { programa integrado de ensino, } \\
\text { pesquisa e extensão universitária } \\
\text { Arte, Cultura, Juventude e } \\
\text { Empreendimentos Criativos, do } \\
\text { Departamento de Terapia } \\
\text { Ocupacional da Universidade } \\
\text { Federal de São Carlos. }\end{array}$ & $\begin{array}{l}\text { Mapeamento de jovens artistas da } \\
\text { cidade de São Carlos, formação e } \\
\text { capacitação dos jovens para } \\
\text { atendimento das demandas } \\
\text { apresentadas, composição de um } \\
\text { grupo pautado no campo da Cultura } \\
\text { em relaçáo com a economia criativa, } \\
\text { com respectiva e avaliação do } \\
\text { processo. }\end{array}$ \\
\hline 9 & $\begin{array}{l}\text { Costa et al. } \\
(2015)\end{array}$ & $\begin{array}{l}\text { Relato de } \\
\text { experiência }\end{array}$ & $\begin{array}{l}\text { Apresenta uma tecnologia, } \\
\text { criada no Projeto de Extensão } \\
\text { Paramec do Departamento de } \\
\text { Engenharia Mecânica da } \\
\text { Universidade Federal de Minas } \\
\text { Gerais, voltada para ajudar na } \\
\text { aprendizagem ou reabilitaçáo de } \\
\text { pessoa em tratamento na Clínica } \\
\text { de Musicoterapia da referida } \\
\text { universidade. }\end{array}$ & $\begin{array}{l}\text { Desenvolvimento de dispositivos de } \\
\text { tecnologia educacional, reabilitadora } \\
\text { ou assistiva, adaptaçóes ou } \\
\text { instrumentos sonoros para auxiliarem } \\
\text { em intervençáo terapêuticas junto as } \\
\text { pessoas com síndrome de down, } \\
\text { paralisia cerebral, déficit intelectual, } \\
\text { depressão, no espectro autista, entre } \\
\text { outros. }\end{array}$ \\
\hline 10 & $\begin{array}{c}\text { Lorezon \& } \\
\text { Marquetti } \\
\text { (2016). }\end{array}$ & $\begin{array}{c}\text { Relato de } \\
\text { experiência }\end{array}$ & $\begin{array}{l}\text { Relata o processo da Oficina de } \\
\text { Ação parte integrante do projeto } \\
\text { de extensão. A açáo como } \\
\text { precursora do pensamento } \\
\text { humano da Universidade } \\
\text { Federal de São Paulo, campus } \\
\text { Santos, para usuários de um } \\
\text { serviço de saúde mental. }\end{array}$ & $\begin{array}{l}\text { Realiza processos de intervenção } \\
\text { terapêutico ocupacional com um } \\
\text { grupo de usuários de um Núcleo de } \\
\text { Atendimento Psicossocial de Santos. } \\
\text { As oficinas propiciavam vivencias que } \\
\text { envolviam sensibilidades corporais, } \\
\text { para com isso serem elaborados os } \\
\text { projetos terapêuticos singulares com } \\
\text { proposição de intervençóes. }\end{array}$ \\
\hline 11 & $\begin{array}{l}\text { Sato et al. } \\
(2014) \text {. }\end{array}$ & Artigo original & $\begin{array}{l}\text { Opinião e comportamento de } \\
\text { pessoas com queixas cognitivas } \\
\text { sobre a participação no } \\
\text { Programa de Estimulação da } \\
\text { Memória (PEM), desenvolvido } \\
\text { pelo Laboratório de } \\
\text { Gerontologia do Curso de } \\
\text { Terapia Ocupacional da } \\
\text { Faculdade de Medicina da } \\
\text { Universidade de São Paulo. }\end{array}$ & $\begin{array}{l}\text { Experiência de compartilhamento de } \\
\text { conhecimentos de pessoas com } 60 \text { anos } \\
\text { ou mais, residentes na comunidade e } \\
\text { participantes de grupos de estimulaçáo } \\
\text { da memória e das funçóes cognitivas } \\
\text { relacionais em Centro Saúde Escola, } \\
\text { Centro de Convivência e Cooperativa. } \\
\text { Os participantes são estimulados a } \\
\text { exporem seus conhecimentos sobre os } \\
\text { assuntos debatidos e refletirem sobre as } \\
\text { possíveis aplicaçóes na vida cotidiana. }\end{array}$ \\
\hline 12 & $\begin{array}{c}\text { Correa \& } \\
\text { Santana }(2014) .\end{array}$ & Artigo original & $\begin{array}{l}\text { Descreve resultados do projeto } \\
\text { de extensão Promoçáo do } \\
\text { Desempenho Ocupacional de } \\
\text { Indivíduos com Disfunção } \\
\text { Visual do curso de Terapia } \\
\text { Ocupacional da Universidade } \\
\text { Federal do Paraná (UFPR). }\end{array}$ & $\begin{array}{l}\text { Intervenção da terapia ocupacional } \\
\text { no desempenho ocupacional de } \\
\text { crianças e adolescentes com } \\
\text { deficiência visual e que } \\
\text { frequentavam o Ensino } \\
\text { Fundamental na Modalidade } \\
\text { Educação Especial na Escola } \\
\text { Professor Osny Macedo Saldanha, } \\
\text { mantido pelo Instituto Paranaense } \\
\text { de Cegos-IPC. }\end{array}$ \\
\hline
\end{tabular}


Tabela 1. Continuação...

\begin{tabular}{|c|c|c|c|c|}
\hline & Autor/ Ano & $\begin{array}{l}\text { Artigo original } \\
\text { ou Relato de } \\
\text { experiência }\end{array}$ & $\begin{array}{c}\text { Temática abordada na } \\
\text { publicaçáo }\end{array}$ & Síntese da atividade de extensáo \\
\hline 13 & $\begin{array}{c}\text { Baldani \& } \\
\text { Castro (2007). }\end{array}$ & Artigo original & $\begin{array}{l}\text { Discute os desdobramentos das } \\
\text { açóes de terapia ocupacional } \\
\text { com uma criança em situação de } \\
\text { risco social a partir do trabalho } \\
\text { de campo realizado no projeto } \\
\text { de extensáo "Ações territoriais } \\
\text { em terapia ocupacional na } \\
\text { interface da Arte e Promoção da } \\
\text { Saúde" da Universidade de Sáo } \\
\text { Paulo, campus São Paulo. }\end{array}$ & $\begin{array}{l}\text { Atendimento de crianças entre } 4 \text { e } 6 \\
\text { anos em risco social na cidade de Sáo } \\
\text { Paulo providas pelo grupo PACTO } \\
\text { em creche, salóes da igreja do bairro, } \\
\text { entre outros espaços. }\end{array}$ \\
\hline 14 & $\begin{array}{l}\text { Castro et al. } \\
\text { (2011). }\end{array}$ & Artigo original & $\begin{array}{l}\text { Análise crítica das práticas que } \\
\text { compuseram o conjunto de } \\
\text { propostas de extensão } \\
\text { universitária do Curso de } \\
\text { Terapia Ocupacional da } \\
\text { Universidade de São Paulo. }\end{array}$ & $\begin{array}{l}\text { Práticas interdisciplinares na } \\
\text { interface da Arte e Saúde junto à } \\
\text { população em vulnerabilidade social } \\
\text { composta por homens e mulheres, } \\
\text { jovens, adultos e idosos, com } \\
\text { enfoque na facilitação ao acesso à } \\
\text { experimentação, criação, produção e } \\
\text { fruição artística e cultural, e } \\
\text { produção de saúde e qualidade na } \\
\text { vida cotidiana. }\end{array}$ \\
\hline 15 & Almeida (2004). & $\begin{array}{c}\text { Relato de } \\
\text { experiência }\end{array}$ & $\begin{array}{l}\text { Descreve uma das experiências } \\
\text { de extensão de promoção de } \\
\text { saúde junto a adolescentes } \\
\text { internos na Unidade } \\
\text { Educacional da FEBEM de } \\
\text { Ribeirão Preto, desenvolvida por } \\
\text { uma terapeuta ocupacional e } \\
\text { alunos de psicologia, como parte } \\
\text { das atividades da equipe do } \\
\text { Núcleo de Estudos e Prevenção } \\
\text { das DST/Aids e Uso indevido de } \\
\text { drogas (NEPDA) do } \\
\text { departamento de Psicologia da } \\
\text { Faculdade de Filosofia, Ciências } \\
\text { e Letras da Universidade de São } \\
\text { Paulo, campus Ribeiráo Preto. }\end{array}$ & $\begin{array}{l}\text { Promoção de um espaço para que os } \\
\text { jovens internos da FEBEM } \\
\text { pudessem expressar suas ideias, } \\
\text { sentimentos, comunicarem-se dentro } \\
\text { e fora da instituição. }\end{array}$ \\
\hline 16 & $\begin{array}{l}\text { Monteiro et al. } \\
\text { (2015). }\end{array}$ & Artigo original & $\begin{array}{l}\text { Descreve as construções das } \\
\text { relaçôes de gênero no discurso de } \\
\text { meninas adolescentes participantes } \\
\text { do projeto de extensão Análise da } \\
\text { Utilização de Recursos Lúdicos na } \\
\text { Promoçáo de Saúde Sexual e } \\
\text { Reprodutiva de Adolescentes do } \\
\text { Departamento de Terapia } \\
\text { Ocupacional da Universidade } \\
\text { Federal de Pernambuco (UFPE). }\end{array}$ & $\begin{array}{l}\text { Intervençóes, por meio de recursos } \\
\text { lúdicos, sobre mudanças no corpo, } \\
\text { sexualidade, relaçóes de gênero, } \\
\text { sexualidade, gravidez e DST, } \\
\text { relacionando o impacto destes no } \\
\text { desempenho ocupacional das } \\
\text { adolescentes do sexo feminino entre } \\
12 \text { a } 15 \text { anos. Análise dos recursos } \\
\text { lúdicos utilizados para a promoçáo } \\
\text { de saúde sexual e reprodutiva das } \\
\text { adolescentes }\end{array}$ \\
\hline
\end{tabular}


Tabela 1. Continuação...

\begin{tabular}{|c|c|c|c|c|}
\hline & Autor/ Ano & $\begin{array}{l}\text { Artigo original } \\
\text { ou Relato de } \\
\text { experiência }\end{array}$ & $\begin{array}{c}\text { Temática abordada na } \\
\text { publicaçáo }\end{array}$ & Síntese da atividade de extensáo \\
\hline 17 & $\begin{array}{c}\text { Justa \& } \\
\text { Holanda } \\
(2012) .\end{array}$ & Artigo original & $\begin{array}{l}\text { Analisa a experiência de extensão } \\
\text { realizada pelo Grupo de } \\
\text { Expressóes Sócio-Teatrais em } \\
\text { Terapia Ocupacional (GESTTO) } \\
\text { do departamento de Terapia } \\
\text { Ocupacional da Universidade de } \\
\text { Fortaleza projeto em parceria com } \\
\text { o Serviço de Terapia Ocupacional } \\
\text { do Núcleo de Atençáo Médica } \\
\text { Integrada (NAMI), Unidade } \\
\text { Saúde subsidiada pela referida } \\
\text { universidade voltado para a } \\
\text { assistência de adolescentes em risco } \\
\text { social. }\end{array}$ & $\begin{array}{l}\text { Promoção da saúde, por meio da } \\
\text { utilizaçáo da linguagem artística do } \\
\text { teatro, junto a adolescentes de } 14 \text { a } \\
18 \text { anos, regularmente matriculados } \\
\text { em escola, moradores da } \\
\text { comunidade do Dendê e em risco } \\
\text { social. }\end{array}$ \\
\hline 18 & $\begin{array}{c}\text { Lima \& Silveira } \\
\text { (2009). }\end{array}$ & Artigo original & $\begin{array}{l}\text { Apresenta o primeiro grupo da } \\
\text { atividade de extensão com } \\
\text { enfoque no idoso morador da } \\
\text { cidade de São Paulo do Programa } \\
\text { Permanente Composiçóes } \\
\text { Artísticas e Terapia Ocupacional } \\
\text { (PACTO) do Departamento de } \\
\text { Terapia Ocupacional da } \\
\text { Universidade de Sáo Paulo, } \\
\text { campus São Paulo. }\end{array}$ & $\begin{array}{l}\text { Propõe um trabalho na interface } \\
\text { arte/saúde que visa à promoção de } \\
\text { um envelhecimento com qualidade } \\
\text { de vida, prevenção e melhora de } \\
\text { fatores de ordem biológica e } \\
\text { psicossocial, ampliando a ação dos } \\
\text { idosos no seu meio, facilitando a } \\
\text { inclusão do sujeito que envelhece em } \\
\text { redes de troca e interação social. }\end{array}$ \\
\hline 19 & $\begin{array}{l}\text { Oliver et al. } \\
\text { (2003). }\end{array}$ & Artigo original & $\begin{array}{l}\text { Apresenta o projeto de ensino, } \\
\text { pesquisa e extensão do } \\
\text { Departamento de Fisioterapia, } \\
\text { Fonoaudiologia e Terapia } \\
\text { Ocupacional da Faculdade de } \\
\text { Medicina da Universidade de } \\
\text { São Paulo, campus São Paulo, } \\
\text { voltado à assistência à } \\
\text { comunidade e pessoas com } \\
\text { deficiências assistidas no Distrito } \\
\text { de Saúde Escola Butantá, zona } \\
\text { oeste de São Paulo e moradoras } \\
\text { na comunidade do Jardim } \\
\text { D’Abril e Jardim Boa Vista em } \\
\text { seu entorno. }\end{array}$ & $\begin{array}{l}\text { Acompanhamento individual para } \\
\text { construção de projetos de vida, } \\
\text { fomento da cidadania e da participação } \\
\text { na vida social, realizaçáo de fóruns para } \\
\text { organização social em torno das } \\
\text { necessidades específicas das pessoas } \\
\text { com deficiência. Transformação da } \\
\text { cultura local a respeito da deficiência } \\
\text { por meio de atividades socioculturais } \\
\text { com circulação em espaços públicos, } \\
\text { trocas sociais e afetivas, facilitação da } \\
\text { convivência entre pessoas com e sem } \\
\text { deficiências, construindo experiências } \\
\text { para uma cultura de validaçáo da } \\
\text { pessoa com deficiência. }\end{array}$ \\
\hline 20 & $\begin{array}{l}\text { Angelli et al. } \\
\text { (2009). }\end{array}$ & Editorial & $\begin{array}{l}\text { Apresentação do grupo PACTO } \\
\text { do Departamento de Terapia } \\
\text { Ocupacional da Universidade de } \\
\text { São Paulo, que tem articulado } \\
\text { ensino, pesquisa e extensão com o } \\
\text { objetivo de favorecer aos seus } \\
\text { participantes a oportunidade de } \\
\text { desenvolver potenciais criativo, } \\
\text { artístico e intelectual. }\end{array}$ & $\begin{array}{l}\text { Desenvolve potenciais criativo, } \\
\text { artístico e intelectual ao acompanhar } \\
\text { pessoas da comunidade, usuários ou } \\
\text { não do serviço de saúde, em } \\
\text { atividades grupais e/ou viabilizar o } \\
\text { acesso a eventos culturais }\end{array}$ \\
\hline
\end{tabular}


Tabela 1. Continuação...

\begin{tabular}{|c|c|c|c|c|}
\hline & Autor/ Ano & $\begin{array}{l}\text { Artigo original } \\
\text { ou Relato de } \\
\text { experiência }\end{array}$ & $\begin{array}{c}\text { Temática abordada na } \\
\text { publicaçáo }\end{array}$ & Síntese da atividade de extensáo \\
\hline 21 & $\begin{array}{c}\text { Coutinho et al. } \\
\text { (2009). }\end{array}$ & Artigo original & $\begin{array}{l}\text { Relata a experiência do } \\
\text { Programa Lazer com Arte para } \\
\text { a Terceira Idade (LAPTI), uma } \\
\text { colaboração entre o } \\
\text { Laboratório de Estudos e } \\
\text { Pesquisas Arte e Corpo em } \\
\text { Terapia Ocupacional do } \\
\text { departamento de Terapia } \\
\text { Ocupacional da Universidade } \\
\text { de Sáo Paulo, campus Sáo } \\
\text { Paulo, e o Museu de Arte } \\
\text { Contemporânea da USP } \\
\text { (MAC USP) focalizando } \\
\text { algumas açóes significativas e } \\
\text { seus desdobramentos para a } \\
\text { construção de práticas de } \\
\text { terapia ocupacional no campo } \\
\text { cultural. }\end{array}$ & $\begin{array}{l}\text { Volta-se para idosos, aposentados ou } \\
\text { não, iniciando-os numa práxis } \\
\text { artística contemporânea. } \\
\text { As atividades são centradas em } \\
\text { práticas de ateliê e apreciação } \\
\text { comentada de obras selecionadas do } \\
\text { acervo do MAC USP em articulação } \\
\text { com as informaçóes que } \\
\text { contextualizam historicamente } \\
\text { obras, artistas e movimentos } \\
\text { artísticos da contemporaneidade. }\end{array}$ \\
\hline 22 & $\begin{array}{c}\text { Gomes et al. } \\
\text { (2014). }\end{array}$ & Artigo Original & $\begin{array}{l}\text { Apresenta os efeitos do } \\
\text { programa de extensão Educação } \\
\text { ao Paciente Reumático do } \\
\text { Departamento de Educação } \\
\text { Integrada em Saúde da } \\
\text { Universidade Federal do Espírito } \\
\text { Santo Universidade Federal do } \\
\text { Espirito Santo em um Serviço de } \\
\text { Reumatologia do Hospital } \\
\text { Universitário Cassiano Antônio } \\
\text { de Moraes em Vitória, Espirito } \\
\text { Santo. }\end{array}$ & $\begin{array}{l}\text { Proporciona ao paciente com } \\
\text { doenças reumáticas, de ambos os } \\
\text { sexos e com idades variadas, o } \\
\text { desenvolvimento de habilidades } \\
\text { pessoais e possibilidades de } \\
\text { enfrentamento da doença por meio } \\
\text { da abordagem grupal. }\end{array}$ \\
\hline 23 & $\begin{array}{c}\text { Dutra et al. } \\
\text { (2018). }\end{array}$ & Artigo original & $\begin{array}{l}\text { Percepção de estudantes e } \\
\text { participantes de três projetos de } \\
\text { extensão Educar para Reciclar, } \\
\text { Assessoria de Eventos } \\
\text { Sustentáveis e Sustentabilidade e } \\
\text { Inovação, do departamento de } \\
\text { Engenharia Ambiental da } \\
\text { Universidade Federal do } \\
\text { Triângulo Mineiro de caráter } \\
\text { socioeducativo, sobre as práticas } \\
\text { sustentáveis mudarem os hábitos } \\
\text { cotidianos e o envolvimento em } \\
\text { ocupaçóes também sustentáveis. }\end{array}$ & $\begin{array}{l}\text { Os projetos tem como foco o } \\
\text { desenvolvimento de práticas } \\
\text { sustentáveis a partir de espaços de } \\
\text { caráter socioeducativos. } \\
\text { Especificamente, o projeto Educar } \\
\text { para Reciclar realiza açóes de } \\
\text { educação ambiental na universidade } \\
\text { e em instituiçóes de ensino da } \\
\text { cidade, visando conscientizar e } \\
\text { sensibilizar as pessoas para a } \\
\text { necessidade da adoçáo de atitudes e } \\
\text { hábitos sustentáveis. O projeto } \\
\text { Assessoria de Eventos Sustentáveis se } \\
\text { dedica a assessorar os eventos } \\
\text { realizados na universidade ou } \\
\text { vinculados à ela. O projeto } \\
\text { Sustentabilidade e Inovação recicla } \\
\text { banners usados e apresenta } \\
\text { alternativas para sua reutilização. }\end{array}$ \\
\hline
\end{tabular}


Tabela 1. Continuação...

\begin{tabular}{|c|c|c|c|c|}
\hline & Autor/ Ano & $\begin{array}{l}\text { Artigo original } \\
\text { ou Relato de } \\
\text { experiência }\end{array}$ & $\begin{array}{c}\text { Temática abordada na } \\
\text { publicaçáo }\end{array}$ & Síntese da atividade de extensáo \\
\hline 24 & $\begin{array}{l}\text { Silva et al. } \\
(2019) \text {. }\end{array}$ & $\begin{array}{c}\text { Relato de } \\
\text { experiência }\end{array}$ & $\begin{array}{l}\text { Apresenta a proposta de } \\
\text { atividade de ensino, pesquisa e } \\
\text { extensão em terapia ocupacional } \\
\text { social, articuladas ao Programa } \\
\text { METUIA, para alunos de } \\
\text { graduação e pós-graduação da } \\
\text { Universidade Federal de São } \\
\text { Carlos (UFSCar). }\end{array}$ & $\begin{array}{l}\text { Oficinas de atividades dramáticas, } \\
\text { plásticas e lúdicas com jovens em } \\
\text { vulnerabilidade social em espaços } \\
\text { públicos de diferentes naturezas } \\
\text { como escola pública estadual, } \\
\text { Centro de Juventude, Centro } \\
\text { Comunitário, cujos objetivos estão } \\
\text { parametrizados pelas noçóes de } \\
\text { cidadania, de direitos/deveres e da } \\
\text { participaçáo democrática. }\end{array}$ \\
\hline 25 & $\begin{array}{c}\text { Francelino \& } \\
\text { Bregalda } \\
(2020) .\end{array}$ & Artigo original & $\begin{array}{l}\text { Apresenta as contribuiçóes do } \\
\text { projeto "Extensão Universitária } \\
\text { em Poesia Ocupacional” do } \\
\text { Departamento de Terapia } \\
\text { Ocupacional da Universidade } \\
\text { Federal da Paraíba, voltado para } \\
\text { a formação dos estudantes do } \\
\text { curso de terapia ocupacional do } \\
\text { referido departamento. }\end{array}$ & $\begin{array}{l}\text { Buscava oportunizar aos discentes do } \\
\text { curso de terapia ocupacional o } \\
\text { exercício de uma compreensão } \\
\text { sensível de si e do outro, que pudesse } \\
\text { repercutir na formação e produçáo } \\
\text { de práticas profissionais mais } \\
\text { sensíveis e humanizadas, por meio } \\
\text { do uso da arte e da poesia. }\end{array}$ \\
\hline 26 & $\begin{array}{c}\text { Della } \\
\text { Barba et al. } \\
(2017) .\end{array}$ & $\begin{array}{c}\text { Relato de } \\
\text { experiência }\end{array}$ & $\begin{array}{l}\text { Vivencias de estudantes de } \\
\text { graduação na atividade de extensão } \\
\text { "Formação de alunos de graduaçáo } \\
\text { em Terapia Ocupacional e de } \\
\text { agentes comunitários de saúde para } \\
\text { a promoção de açóes de vigilância } \\
\text { do desenvolvimento infantil na } \\
\text { atenção primária à saúde" do } \\
\text { Departamento de Terapia } \\
\text { Ocupacional da Universidade } \\
\text { Federal de Sáo Carlos. }\end{array}$ & $\begin{array}{l}\text { Formação e capacitação de } \\
\text { estudantes do curso de terapia } \\
\text { ocupacional, de agentes } \\
\text { comunitários de saúde e de } \\
\text { familiares a respeito da vigilância do } \\
\text { desenvolvimento infantil e de açóes } \\
\text { de cuidado integral à criança na } \\
\text { atenção primária à saúde. }\end{array}$ \\
\hline 27 & $\begin{array}{l}\text { Silva et al. } \\
\text { (2018b). }\end{array}$ & $\begin{array}{l}\text { Relato de } \\
\text { experiência }\end{array}$ & $\begin{array}{l}\text { Relata a experiência oriunda de } \\
\text { um compilado de projetos de } \\
\text { extensão universitária voltado à } \\
\text { população em situaçáo de rua e } \\
\text { com foco realizado no Centro de } \\
\text { Referência Especializado de } \\
\text { Assistência Social da Populaçáo } \\
\text { em Situaçáo de Rua da cidade de } \\
\text { São Carlos. }\end{array}$ & $\begin{array}{l}\text { Atuação a partir da arte e da cultura } \\
\text { para promoçáo de estratégias } \\
\text { criativas e oferta à população em } \\
\text { situação de rua de espaços de } \\
\text { pertencimento, construção e } \\
\text { fortalecimento de redes sociais de } \\
\text { suporte e de vínculos para promoção } \\
\text { de fazeres, criaçóes e } \\
\text { experimentaçôes. }\end{array}$ \\
\hline 28 & $\begin{array}{l}\text { Meneses et al. } \\
\text { (2016). }\end{array}$ & $\begin{array}{l}\text { Relato de } \\
\text { experiência }\end{array}$ & $\begin{array}{l}\text { Relata a implantação e } \\
\text { desenvolvimento do projeto de } \\
\text { extensão universitária TO } \\
\text { Clicando do Departamento de } \\
\text { Terapia Ocupacional da } \\
\text { Universidade de Brasília, } \\
\text { campus Ceilândia, descrevendo } \\
\text { suas características, seus } \\
\text { objetivos e suas contribuiçóes } \\
\text { acadêmicas e comunitárias. }\end{array}$ & $\begin{array}{l}\text { Objetiva promover a inclusão social e } \\
\text { digital de idosos residentes na } \\
\text { comunidade ou em instituição de longa } \\
\text { permanência, por meio de oficinas de } \\
\text { informática, oficinas de estimulação } \\
\text { cognitiva, oficinas de lazer e atividades } \\
\text { manuais, palestras informativas e } \\
\text { atividades de socialização }\end{array}$ \\
\hline
\end{tabular}


Tabela 1. Continuação...

\begin{tabular}{|c|c|c|c|c|}
\hline & Autor/ Ano & $\begin{array}{l}\text { Artigo original } \\
\text { ou Relato de } \\
\text { experiência }\end{array}$ & $\begin{array}{c}\text { Temática abordada na } \\
\text { publicaçáo }\end{array}$ & Síntese da atividade de extensáo \\
\hline 29 & $\begin{array}{l}\text { Silva et al. } \\
\text { (2015a). }\end{array}$ & $\begin{array}{c}\text { Relato de } \\
\text { experiência }\end{array}$ & $\begin{array}{l}\text { Descreve a atuação do terapeuta } \\
\text { ocupacional no projeto de } \\
\text { extensão Doce Vida voltado ao } \\
\text { atendimento de adultos e idosos } \\
\text { com sobrepeso e obesidade, na } \\
\text { cidade de Natal. }\end{array}$ & $\begin{array}{l}\text { Fornece educação em saúde através } \\
\text { de atividades terapêuticas } \\
\text { ocupacionais lúdicas, cognitivas, } \\
\text { corporais, físicas e produtivas. }\end{array}$ \\
\hline 30 & $\begin{array}{l}\text { Macedo et al. } \\
\text { (2016). }\end{array}$ & Artigo original & $\begin{array}{l}\text { Através de relatos de estudantes } \\
\text { do projeto de extensão terapia } \\
\text { ocupacional e os Jovens Guarani } \\
\text { do Espírito Santo: Diálogos e } \\
\text { Oficinas Culturais, do } \\
\text { Departamento de Terapia } \\
\text { Ocupacional da Universidade } \\
\text { Federal do Espirito Santo, são } \\
\text { articulados e aprofundados os } \\
\text { conhecimentos teórico- } \\
\text { metodológicos da terapia } \\
\text { ocupacional junto ao povo } \\
\text { Guarani, desvelando as questôes } \\
\text { de etnicidade e cultura, e sua } \\
\text { relação com as açóes técnicas, do } \\
\text { terapeuta ocupacional. }\end{array}$ & $\begin{array}{l}\text { Criação de intervenções, com enfoque } \\
\text { na problematização de questôes } \\
\text { identitárias, socialização e interação } \\
\text { entre os jovens Guarani, Tupiniquim } \\
\text { das aldeias de Aracruz e de outras } \\
\text { comunidades Guarani, de atividades } \\
\text { em grupos, oficinas de atividades, } \\
\text { atividades comunitárias e } \\
\text { acompanhamentos individuais junto } \\
\text { às crianças e aos jovens. A partir da } \\
\text { inserção dos estudantes de terapia } \\
\text { ocupacional na aldeia Guarani Três } \\
\text { Palmeiras, na cidade de Aracruz, } \\
\text { localizada no litoral capixaba, distante } \\
83 \text { km da capital, Vitória, são } \\
\text { pensados instrumentos e recursos, } \\
\text { como o teatro, a dança, o desenho, os } \\
\text { jogos, as reunióes comunitárias, os } \\
\text { mutiróes para a organizaçáo física do } \\
\text { espaço territorial, além de recursos } \\
\text { multimeios e de materiais produzidos } \\
\text { pelos próprios índios, como } \\
\text { documentários, textos e blogs. }\end{array}$ \\
\hline 31 & $\begin{array}{c}\text { Angeli \& } \\
\text { Fonseca (2015). }\end{array}$ & Artigo original & $\begin{array}{l}\text { Apresenta parte das } \\
\text { problemáticas, reflexóes e } \\
\text { potencialidades vividas pela } \\
\text { docente e pelos estudantes de } \\
\text { graduaçáo em terapia } \\
\text { ocupacional, no período de } \\
\text { 2010-2014 (estagiários, } \\
\text { voluntários e bolsistas), na } \\
\text { construçáo do Projeto TOCCA } \\
\text { - Terapia Ocupacional, Corpo, } \\
\text { Cultura e Artes - do curso de } \\
\text { Terapia Ocupacional da } \\
\text { Universidade Federal de Santa } \\
\text { Maria. }\end{array}$ & $\begin{array}{l}\text { O projeto se insere na rede de } \\
\text { proteçáo básica da zona leste da } \\
\text { cidade fazendo interlocuçóes com o } \\
\text { Centro de Assistência Social e com } \\
\text { algumas instituiçóes que compóem a } \\
\text { rede socioassistencial desta regiáo. } \\
\text { Em especial, atuava junto à } \\
\text { associação de moradores do } \\
\text { loteamento "Estação dos Ventos" e à } \\
\text { Unidade de Proteção Integral, o } \\
\text { projeto social da Casa Espírita } \\
\text { Fernando do Ó. Parte das açóes da } \\
\text { equipe também acontece no } \\
\text { acompanhamento regular das } \\
\text { reunióes do Conselho Municipal de } \\
\text { Assistência Social e, eventualmente, } \\
\text { das reunióes do Conselho Municipal } \\
\text { de Direitos da Criança e do } \\
\text { Adolescente. }\end{array}$ \\
\hline
\end{tabular}


Tabela 1. Continuação...

\begin{tabular}{|c|c|c|c|c|}
\hline & Autor/ Ano & $\begin{array}{l}\text { Artigo original } \\
\text { ou Relato de } \\
\text { experiência }\end{array}$ & $\begin{array}{c}\text { Temática abordada na } \\
\text { publicaçáo }\end{array}$ & Síntese da atividade de extensão \\
\hline 32 & $\begin{array}{l}\text { Bardi et al. } \\
\text { (2016). }\end{array}$ & $\begin{array}{c}\text { Relato de } \\
\text { experiência }\end{array}$ & $\begin{array}{l}\text { Relata a experiência do } \\
\text { programa METUIA do } \\
\text { Departamento de Terapia } \\
\text { Ocupacional da Universidade } \\
\text { Federal do Espírito Santo, que } \\
\text { ilustra, sob a ótica da terapia } \\
\text { ocupacional social, as oficinas } \\
\text { culturais e os acompanhamentos } \\
\text { individuais e territoriais } \\
\text { empreendidos durante um } \\
\text { período de seis meses, no } \\
\text { contexto sociocultural de uma } \\
\text { comunidade periférica do } \\
\text { município de Vitória, ES. }\end{array}$ & $\begin{array}{l}\text { Potencializar crianças e jovens do } \\
\text { Bairro Santos Reis, pertencente à } \\
\text { Região de São Pedro, Espirito Santo, } \\
\text { no sentido da apropriação do espaço } \\
\text { comunitário, construindo em conjunto } \\
\text { formas de autonomia e participação } \\
\text { social e fortalecendo seus desejos e } \\
\text { projetos de vida, de acordo com a } \\
\text { cultura local. Realizaçáo de açóes e } \\
\text { atividades intersetoriais no que tange à } \\
\text { saúde, à educação, à assistência social, } \\
\text { ao esporte, à cultura e ao lazer, } \\
\text { promovendo reflexóes sobre as } \\
\text { diferenças e problemáticas sociais no } \\
\text { cotidiano próprio da juventude deste } \\
\text { local. }\end{array}$ \\
\hline 33 & $\begin{array}{l}\text { Luiz \& Macedo } \\
\qquad(2013) .\end{array}$ & Artigo original & $\begin{array}{l}\text { Descreve a realização do projeto } \\
\text { de extensão "Natação e } \\
\text { Atividades Aquáticas para } \\
\text { Populaçóes Especiais" do } \\
\text { departamento de Terapia } \\
\text { Ocupacional da Universidade } \\
\text { Federal de São Carlos, que tinha } \\
\text { por objetivo atendimento da } \\
\text { Terapia Ocupacional no meio } \\
\text { aquático para populaçóes com } \\
\text { necessidades especiais. }\end{array}$ & $\begin{array}{l}\text { Melhoria da qualidade de vida de } \\
\text { crianças e seus acompanhantes, } \\
\text { adolescentes e adultos com necessidades } \\
\text { especiais da cidade de São Carlos. O } \\
\text { atendimento da Terapia Ocupacional } \\
\text { no meio aquático tinha por objetivo o } \\
\text { aumento da consciência corporal, } \\
\text { desenvolvimento motor, sensorial e } \\
\text { cognitivo, promoçáo da autoestima e } \\
\text { realizaçáo pessoal, desenvolvimento da } \\
\text { criatividade, afetividade e socializaçáo. }\end{array}$ \\
\hline 34 & $\begin{array}{l}\text { Joaquim et al. } \\
\text { (2014). }\end{array}$ & $\begin{array}{l}\text { Relato de } \\
\text { experiência }\end{array}$ & $\begin{array}{l}\text { Apresentação da atividade de } \\
\text { extensão grupo de mães de bebês } \\
\text { prematuros hospitalizados numa } \\
\text { Santa Casa de Misericórdia do } \\
\text { interior do estado de São Paulo, } \\
\text { idealizada e concretizada por } \\
\text { docente do Departamento de } \\
\text { Terapia Ocupacional da } \\
\text { Universidade Federal de São } \\
\text { Carlos. }\end{array}$ & $\begin{array}{l}\text { Promoção de suporte, informação e } \\
\text { orientação sobre cuidados e interação } \\
\text { das mães com seus bebês hospitalizados } \\
\text { por meio da proposiçáo de atividades } \\
\text { em grupo pela Terapia Ocupacional. } \\
\text { As atividades eram idealizadas para } \\
\text { auxiliar as mães no enfrentamento da } \\
\text { situação vivenciada de uma maneira } \\
\text { mais saudável e próxima de um } \\
\text { cotidiano reconhecido. As atividades } \\
\text { também focavam o cuidar dos filhos } \\
\text { durante e após a alta hospitalar. O } \\
\text { grupo constituía um lugar no qual as } \\
\text { mães podiam se expor e compartilhar } \\
\text { suas angústias, medos e sofrimentos, } \\
\text { para minimizarem esses sentimentos, } \\
\text { além de conversarem e refletirem sobre } \\
\text { como reorganizar o cotidiano, visualizar } \\
\text { redes de apoio, na família ou fora dela, e } \\
\text { reconhecer sua autonomia e } \\
\text { potencialidade para esse cuidado. }\end{array}$ \\
\hline
\end{tabular}


Tabela 1. Continuação...

\begin{tabular}{|c|c|c|c|c|}
\hline & Autor/ Ano & $\begin{array}{l}\text { Artigo original } \\
\text { ou Relato de } \\
\text { experiência }\end{array}$ & $\begin{array}{c}\text { Temática abordada na } \\
\text { publicaçáo }\end{array}$ & Síntese da atividade de extensáo \\
\hline 35 & $\begin{array}{l}\text { Oliveira et al. } \\
\text { (2003). }\end{array}$ & Artigo original & $\begin{array}{l}\text { Apresenta reflexóes e } \\
\text { experiências do tratamento } \\
\text { resultantes do projeto de } \\
\text { extensão Intervenção de Terapia } \\
\text { Ocupacional em Oncologia do } \\
\text { departamento de Terapia } \\
\text { Ocupacional da Universidade } \\
\text { Federal de São Carlos. }\end{array}$ & $\begin{array}{l}\text { Intervenção terapêutica ocupacional } \\
\text { junto as pessoas em tratamento } \\
\text { oncológico considerando os aspectos } \\
\text { biológicos, psicológicos, sociais e } \\
\text { culturais de cada indivíduo. } \\
\text { Proporcionar aos alunos do curso de } \\
\text { Terapia Ocupacional a experiência } \\
\text { no campo de atuação da profissão } \\
\text { em oncologia e com clientela } \\
\text { atendida, visando para além dos } \\
\text { processos clínicos. }\end{array}$ \\
\hline 36 & Zanni (2005). & Artigo original & $\begin{array}{l}\text { Descreve a realização de } \\
\text { atendimentos provenientes do } \\
\text { projeto de extensão A } \\
\text { Intervenção da Terapia } \\
\text { Ocupacional na Água do } \\
\text { departamento de Terapia } \\
\text { Ocupacional da Universidade } \\
\text { Federal de São Carlos, que } \\
\text { fornecia atendimento da Terapia } \\
\text { Ocupacional no meio aquático } \\
\text { para um adolescente no espectro } \\
\text { autista. }\end{array}$ & $\begin{array}{l}\text { Melhora no relacionamento } \\
\text { interpessoal e redução de } \\
\text { comportamentos agressivos de um } \\
\text { adolescente de } 17 \text { anos no espectro } \\
\text { autista por meio da terapia } \\
\text { ocupacional no meio aquático, na } \\
\text { cidade de Sáo Carlos. }\end{array}$ \\
\hline 37 & $\begin{array}{l}\text { Peruzzolo et al. } \\
\qquad(2015) \text {. }\end{array}$ & Artigo original & $\begin{array}{l}\text { Narra os caminhos teórico- } \\
\text { práticos do processo de } \\
\text { intervenção precoce de um bebê } \\
\text { prematuro, oferecido pelo } \\
\text { programa de extensão "Detecção } \\
\text { e Estimulação Precoce: uma } \\
\text { Perspectiva Interdisciplinar" } \\
\text { vinculados aos cursos de Terapia } \\
\text { Ocupacional e Fonoaudiologia } \\
\text { de uma universidade federal de } \\
\text { uma cidade do interior do Rio } \\
\text { Grande do Sul. }\end{array}$ & $\begin{array}{l}\text { Realização de avaliação do bebê, } \\
\text { coleta de informaçóes com a mãe e } \\
\text { discussão do caso em equipe. } \\
\text { Elaboração e implementação de } \\
\text { intervenção terapêutica ocupacional } \\
\text { baseada nos aportes teórico-práticos } \\
\text { relativos aos conceitos da clínica em } \\
\text { estimulação precoce e psicomotora. } \\
\text { Favorecer a construção de esquema } \\
\text { corporal e da elaboração de uma } \\
\text { nova imagem corporal para o } \\
\text { menino atendido que nasceu } \\
\text { prematuro, sob a óptica da } \\
\text { construçáo subjetiva de um novo } \\
\text { lugar no cotidiano familiar. }\end{array}$ \\
\hline 38 & $\begin{array}{l}\text { Carrasco } \\
(2005)\end{array}$ & Artigo original & $\begin{array}{l}\text { Descreve uma intervenção } \\
\text { proposta através de um projeto } \\
\text { de extensão junto a um berçário } \\
\text { de uma creche municipal em um } \\
\text { bairro da periferia. }\end{array}$ & $\begin{array}{l}\text { Intervenção da terapia ocupacional } \\
\text { no contexto da educaçáo infantil, } \\
\text { especificamente em uma creche para } \\
\text { crianças de } 0 \text { a } 2 \text { anos e as } \\
\text { educadoras. Objetivava a reflexão e } \\
\text { transformação do modelo de } \\
\text { compreensão da infância pela } \\
\text { instituição e pelas educadoras, assim } \\
\text { como a visáo que possuíam sobre o } \\
\text { papel da instituição na vida da } \\
\text { criança e como poderiam realizar um }\end{array}$ \\
\hline
\end{tabular}


Tabela 1. Continuação...

\begin{tabular}{|c|c|c|c|c|}
\hline & Autor/ Ano & $\begin{array}{c}\text { Artigo original } \\
\text { ou Relato de } \\
\text { experiência }\end{array}$ & $\begin{array}{c}\text { Temática abordada na } \\
\text { publicaçáo }\end{array}$ & Síntese da atividade de extensáo \\
\hline & & & & $\begin{array}{l}\text { processo ativo de construção do } \\
\text { próprio ambiente de trabalho. As } \\
\text { ações propostas partiram da } \\
\text { consideração de que a criança é um } \\
\text { ser ativo e capaz de fazer escolhas em } \\
\text { seu processo de desenvolvimento. }\end{array}$ \\
\hline 39 & $\begin{array}{l}\text { Silva et al. } \\
(2015 b) \text {. }\end{array}$ & Artigo original & $\begin{array}{l}\text { Relata a experiência do projeto } \\
\text { de extensão Talentos Juvenis do } \\
\text { Gonzaga do departamento de } \\
\text { Terapia Ocupacional da } \\
\text { Universidade Federal de São } \\
\text { Carlos analisando a utilização de } \\
\text { recursos midiáticos e interativos } \\
\text { para a potencializaçáo de sujeitos } \\
\text { em situação de vulnerabilidade e } \\
\text { ampliação das possibilidades de } \\
\text { comunicação e de participação } \\
\text { social. }\end{array}$ & $\begin{array}{l}\text { Promoção de espaços de criação e } \\
\text { emancipação, fomento da arte e a } \\
\text { cultura, desenvolvimento de oficinas } \\
\text { de atividades com elaboração e a } \\
\text { utilização de um blog, entre outros } \\
\text { recursos midiáticos, com } \\
\text { adolescentes e jovens em situação de } \\
\text { vulnerabilidade social frequentadores } \\
\text { do Centro da Juventude Elaine } \\
\text { Viviane. }\end{array}$ \\
\hline 40 & $\begin{array}{l}\text { Joaquim et al. } \\
\text { (2016). }\end{array}$ & $\begin{array}{l}\text { Relato de } \\
\text { experiência }\end{array}$ & $\begin{array}{l}\text { Descreve o processo de ensino e } \\
\text { aprendizagem de estudantes de } \\
\text { terapia ocupacional em um } \\
\text { projeto de extensão do } \\
\text { departamento de Terapia } \\
\text { Ocupacional da Universidade } \\
\text { Federal de São Carlos voltado } \\
\text { para o acompanhamento da díade } \\
\text { mãe-bebê de risco em berçário } \\
\text { sem intensivo, de um hospital de } \\
\text { uma cidade do interior do Estado } \\
\text { de São Paulo, no domicílio após a } \\
\text { alta hospitalar. }\end{array}$ & $\begin{array}{l}\text { Qualificação das estudantes para a } \\
\text { compreensão do nascimento de } \\
\text { risco, da vinculação inicial mãe-bebê } \\
\text { no ambiente hospitalar, do } \\
\text { acompanhamento do } \\
\text { desenvolvimento infantil e para a } \\
\text { resolução de problemas, além de } \\
\text { compreensão de si enquanto sujeito } \\
\text { de sua própria formação. }\end{array}$ \\
\hline 41 & $\begin{array}{r}\text { Della Barba \& } \\
\text { Minatel (2013). }\end{array}$ & $\begin{array}{l}\text { Relato de } \\
\text { experiência }\end{array}$ & $\begin{array}{l}\text { Relata a experiência da atuação } \\
\text { do terapeuta ocupacional no } \\
\text { projeto de extensão "Consultoria } \\
\text { Colaborativa na Inclusão Escolar } \\
\text { de Crianças com Transtornos de } \\
\text { Desenvolvimento Proposta de } \\
\text { Atuação da Terapia } \\
\text { Ocupacional", do departamento } \\
\text { de Terapia Ocupacional da } \\
\text { Universidade Federal de São } \\
\text { Carlos. }\end{array}$ & $\begin{array}{l}\text { Fornecimento de consultoria } \\
\text { colaborativa em duas escolas de } \\
\text { educação infantil da rede regular de } \\
\text { ensino localizadas em cidades de } \\
\text { pequeno porte na região do } \\
\text { município de São Carlos, suporte e } \\
\text { orientações quanto às possibilidades } \\
\text { de inclusão escolar de crianças com } \\
\text { transtornos de desenvolvimento. }\end{array}$ \\
\hline 42 & $\begin{array}{l}\text { Almeida et al. } \\
\text { (2015). }\end{array}$ & $\begin{array}{l}\text { Relato de } \\
\text { experiência }\end{array}$ & $\begin{array}{l}\text { Apresentar e discutir as } \\
\text { referências conceituais e práticas } \\
\text { do projeto de extensão O } \\
\text { Território e seus Protagonistas: } \\
\text { Novos Olhares para a Infância e } \\
\text { Juventude, desenvolvido pelo } \\
\text { núcleo do Projeto Metuia do }\end{array}$ & $\begin{array}{l}\text { Atividades e situaçóes em terapia } \\
\text { ocupacional social com foco na } \\
\text { juventude, suas famílias e nos } \\
\text { profissionais do Centro de } \\
\text { Referencia em Assistência Social dos } \\
\text { distritos Vila Sônia, Butantá, } \\
\text { Morumbi, Rio Pequeno e Raposo }\end{array}$ \\
\hline
\end{tabular}


Tabela 1. Continuação...

\begin{tabular}{|c|c|c|c|c|}
\hline & Autor/ Ano & $\begin{array}{l}\text { Artigo original } \\
\text { ou Relato de } \\
\text { experiência }\end{array}$ & $\begin{array}{c}\text { Temática abordada na } \\
\text { publicaçáo }\end{array}$ & Síntese da atividade de extensáo \\
\hline & & & $\begin{array}{l}\text { Departamento de Terapia } \\
\text { Ocupacional da Universidade de } \\
\text { Sáo Paulo, campus Sáo Paulo. }\end{array}$ & $\begin{array}{l}\text { Tavares do Butantã. Possibilitar a } \\
\text { construção coletiva de novos pontos } \\
\text { de vista acerca da infância e da } \\
\text { juventude e, em especial, sobre } \\
\text { aqueles considerados em situaçáo de } \\
\text { vulnerabilidade ou de risco social. }\end{array}$ \\
\hline 43 & $\begin{array}{l}\text { Joaquim et al. } \\
\text { (2010). }\end{array}$ & $\begin{array}{l}\text { Relato de } \\
\text { experiência }\end{array}$ & $\begin{array}{l}\text { Descreve a implantação do } \\
\text { projeto de extensão Resgate do } \\
\text { Cotidiano de Jogos e } \\
\text { Brincadeiras para Bebês e } \\
\text { Crianças em Enfermaria } \\
\text { Pediátrica do departamento de } \\
\text { Terapia Ocupacional da } \\
\text { Universidade Federal de São } \\
\text { Carlos. }\end{array}$ & $\begin{array}{l}\text { Fornece o resgate da rotina de } \\
\text { atividades lúdicas, durante o período } \\
\text { de internaçáo e que sejam adequadas } \\
\text { à condiçáo clínica e faixa etária de } \\
\text { bebes e crianças internadas em } \\
\text { enfermaria pediátrica de um hospital } \\
\text { no interior de São Paulo. }\end{array}$ \\
\hline
\end{tabular}

Sobre o período de ocorrência das atividades de extensão, foram encontradas ações com tempos distintos de execução. Têm-se projetos que pontuam a duração de até 6 meses $(n=4)$, projetos que duraram de 6 meses a 1 ano $(n=11)$, aqueles que tiveram a duração de suas atividades no período de 1 a 5 anos $(n=11)$ e projetos que referem sua existência por 5 ou mais anos $(n=14)$, sendo que 3 publicaçóes não especificaram a duração das atividades.

Em relação à equipe de trabalho das atividades, estas foram coordenadas por docentes terapeutas ocupacionais $(n=43)$ e por docentes de outras áreas $(n=2)$ e composta por discentes do curso de graduaçáo em terapia ocupacional $(n=35)$, discentes de outro curso de graduação $(n=7)$, discentes da pós-graduação $(n=4)$, profissionais terapeutas ocupacionais do local em que a extensão era realizada $(n=13)$, técnicos administrativos da UFSCar $(\mathrm{n}=2)$, psicólogo $(\mathrm{n}=2)$, músico $(\mathrm{n}=2)$, médico $(\mathrm{n}=2)$, arte educadores $(\mathrm{n}=2)$, fonoaudiólogo $(\mathrm{n}=1)$, nutricionista $(\mathrm{n}=1)$, artista $(\mathrm{n}=1)$ e curador de arte $(n=1)$.

Os locais em que as atividades extensionistas ocorreram foram diversos e algumas atividades ocorreram em mais de um local, sendo estes os laboratórios de ensino, pesquisa e extensão $(n=9)$, espaços ou serviços vinculados a serviços da assistência social $(n=9)$, hospital $(n=6)$, serviços saúde-escola $(n=5)$, escolas $(n=4)$, centros de convivência $(n=4)$, creches $(n=3)$, academia de natação $(n=2)$, espaços cedidos por instituiçóes religiosas $(n=2)$, Febem (atual Instituição Casa, $n=1)$, domicílio $(n=1)$. Em 4 publicaçôes, os locais não foram especificados.

O público alvo, participantes e/ou protagonistas das atividades de extensão também foram variados e abrangeram todos ciclos ou cursos de vida. Nas figuras a seguir, ilustramos as características, identificaçóes, entre outras referências para abordar os participantes das atividades, agrupados por: bebês e crianças (Figura 2); adolescentes e jovens (Figura 3); adultos e idosos (Figura 4). 


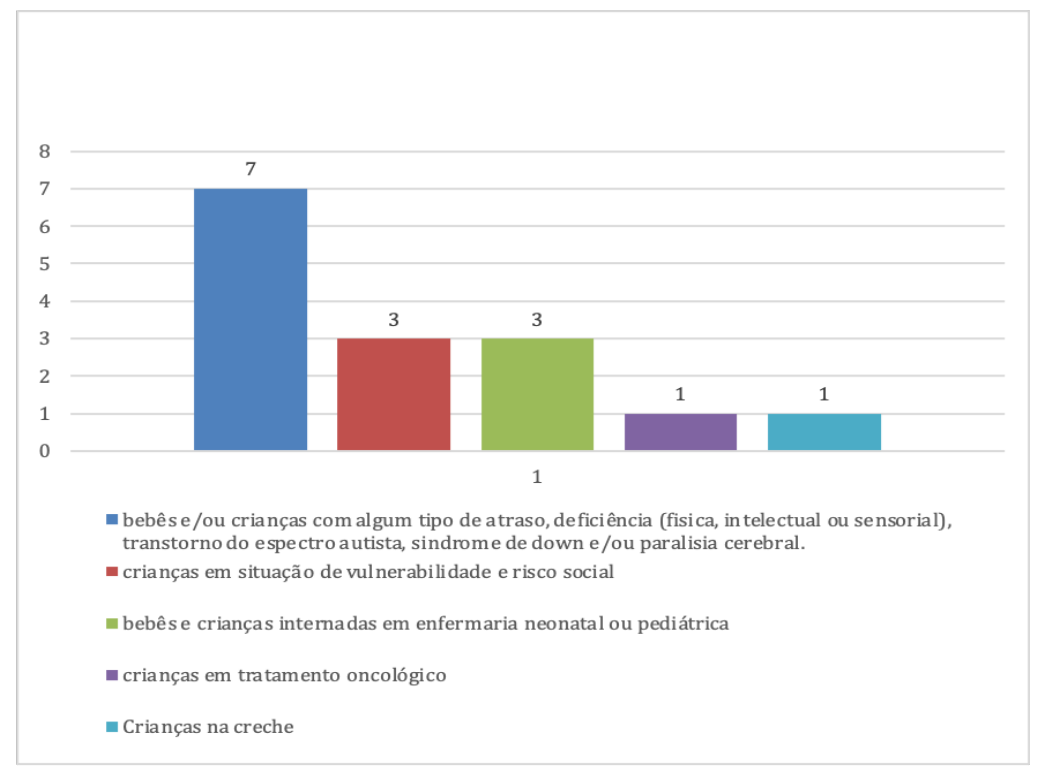

Figura 2. Caracterização dos bebês e crianças.

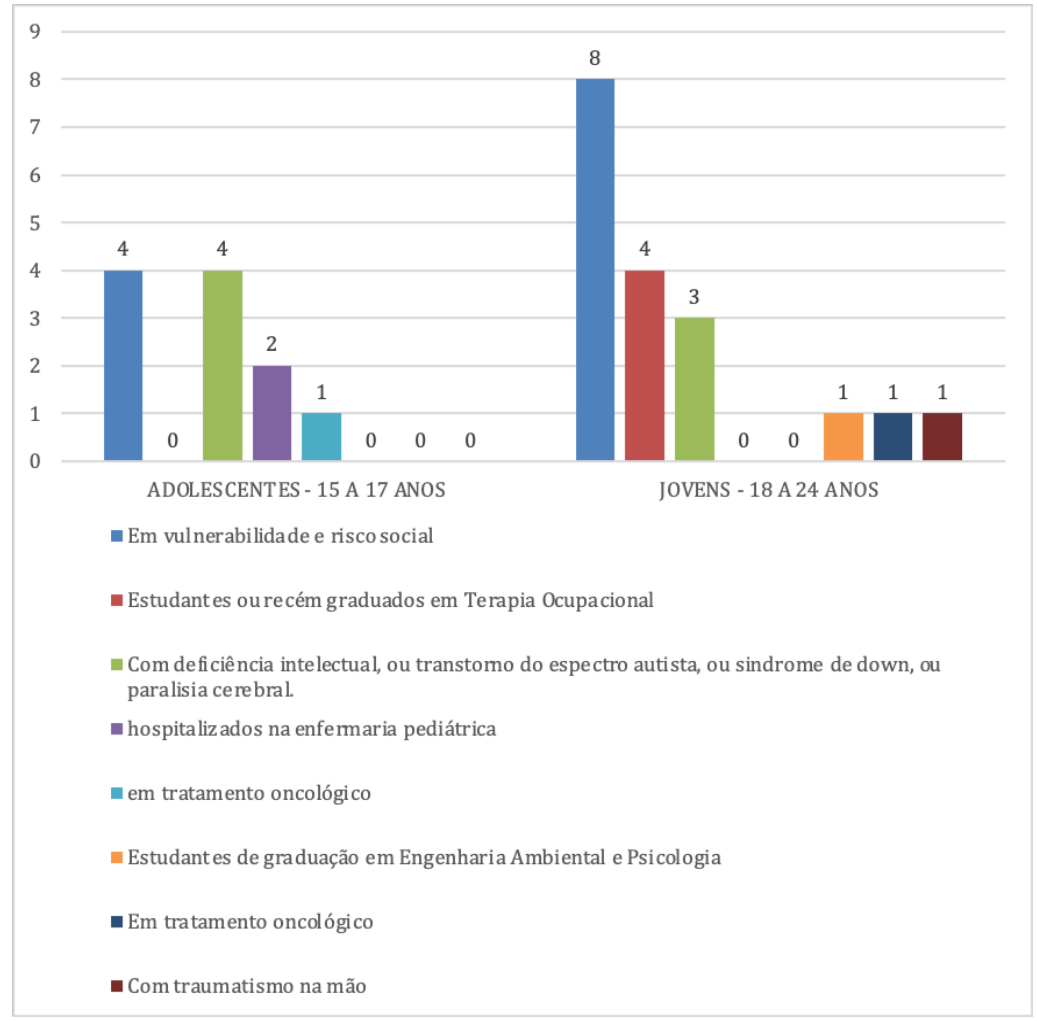

Figura 3. Caracterizaçáo dos adolescentes e jovens. 


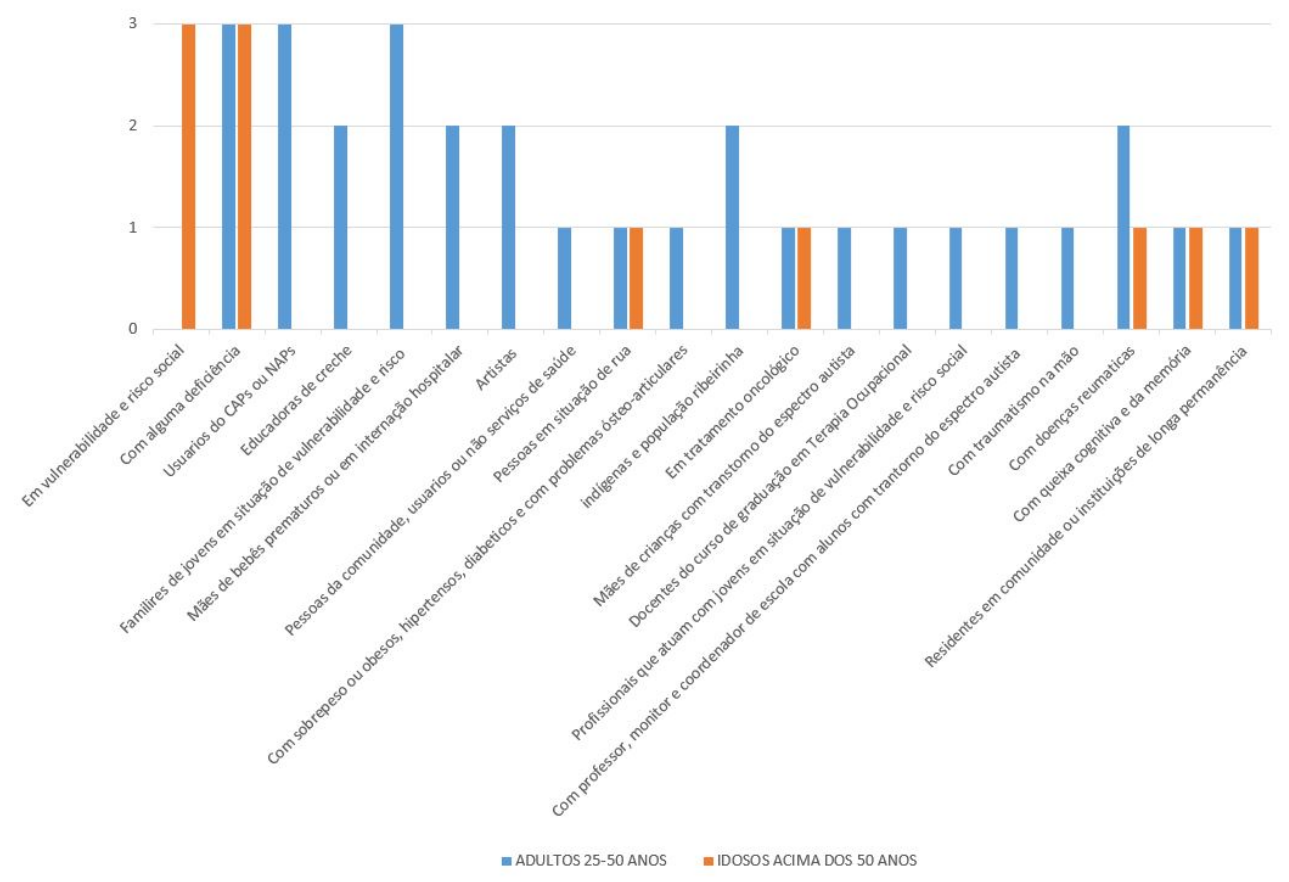

Figura 4. Caracterização dos adultos e idosos.

Dentre as 43 publicaçóes que constituíram a amostra, verificou-se que, em algumas publicaçóes, havia a reflexão e debate de temas como a indissociabilidade entre extensão, ensino e pesquisa, relação entre a universidade e a sociedade, o papel da extensão no processo de ensino-aprendizagem e o impacto da extensão na formação discente e docente. Algumas publicaçóes continham mais de um destes temas, que serão apresentados abaixo agrupados em respectivas categorias temáticas.

\section{Indissociabilidade entre a Extensáo, o Ensino e a Pesquisa}

Algumas publicaçóes referiram que a extensão universitária tem ocorrido de forma indissociável com o ensino e a pesquisa.

Para Meneses et al. (2016), o projeto de extensão desenvolvido em inclusão social e digital de idosos tem permitido uma importante articulação entre ensino, pesquisa e extensão universitária com a participação de docentes, discentes bolsistas e voluntários.

Vários autores referiram que seus projetos concretizados, no âmbito da terapia ocupacional em interface com distintas áreas ou campos, como, por exemplo, da reabilitação com ênfase no território de Oliver et al. (2003), da saúde da criança e do adolescente de Galheigo \& Angeli (2008), da arte com a saúde de Angelli et al. (2009), da educação de pessoas com artrite de Gomes et al. (2014), na saúde de pessoas com sobrepeso e obesidade de Silva et al. (2015a) ou da cultura em relação com a economia criativa de Silva et al. (2018a), foram idealizados e concretizados na interconexão com o ensino e a pesquisa. 
Della Barba et al. (2017) e Angeli \& Fonseca (2015) apontam que a construção de projetos de ensino, pesquisa e extensão em terapia ocupacional, simultaneamente à constituição do curso de graduação, vem sendo a realidade de docentes de universidades públicas.

Della Barba et al. (2015), especificamente sobre a Atividade Curricular de Integração Ensino, Pesquisa e Extensão (ACIEPE) concretizada, explicam que se trata de uma experiência educativa, cultural e científica que envolve professores, técnicos e alunos, com o intuito de estimular o relacionamento de diferentes segmentos da sociedade por meio da articulaçáo do ensino, pesquisa e extensão.

Macedo et al. (2016) referem que os projetos de extensão são passíveis de se desdobrarem em campo de pesquisa, desenvolvendo estudos que envolvam tanto a comunidade à qual se oferta as atividades extensionistas como o corpo docente, discente e técnico envolvidos no processo das práticas. Neste sentido, Joaquim et al. (2016), objetivando enriquecer o processo de ensino e pesquisa com a extensão, definiram como questão investigativa como ensinar alunas de terapia ocupacional a atuar com mães no contexto da hospitalização de seus bebês, partindo da hipótese de que o aprendizado significativo é oriundo da articulação entre fundamentação teórica provida pelo ensino, da prática vivenciada com a extensão e da reflexão adjacente a pesquisa.

Dutra et al. (2018) mencionam que a relação da extensão com o ensino está vinculada tanto ao processo de formação de pessoas como de geração de conhecimento, sendo o estudante um protagonista de sua formação.

Nesta direção, Coutinho et al. (2009) indicam que, pela extensão, cria-se também um avanço nas discussóes acadêmicas, sistematizaçôes e trocas de experiências, conduzindo à construção de modelos teóricos e metodológicos que subsidiem o desenvolvimento de pesquisas em terapia ocupacional, conforme especificidade da área ou campo em foco.

Lima et al. (2016) relatam que, a partir das experiências da extensão, pesquisas são desenvolvidas, como a de avaliação da efetividade da própria atividade extensionista junto aos participantes.

\section{A atividade de extensáo favorecendo a relação da Universidade com a Comunidade}

Em algumas publicações, a atividade de extensão foi indicada como favorecedora da relação entre a universidade e a comunidade, possibilitando que a primeira forneça assistência e cuidado para demandas reais de diferentes pessoas, grupos e comunidades, cumprindo com isso parte de seu compromisso social.

Esta relação foi evidenciada por Correia \& Akerman (2015), que referiram que a extensão universitária se caracteriza como uma prática comunicativa entre a instituição de ensino superior com o contexto sócio comunitário, por meio de açóes concretas e contextualizadas numa dada realidade social que geram uma relação mútua e dialógica entre os atores que permite o engajamento destes nas transformaçóes de suas questôes sociais.

Exemplos de práticas comunicativas entre universidade e sociedade são referidas nas propostas extensionistas de Lima et al. (2016), que atuaram na prevenção e promoção da saúde de trabalhadores músicos; de Alves et al. (2012), que forneceram atendimento a pacientes com lesão ou trauma da mão; de Noordhoek et al. (2009), na proposta de grupo de orientação as pessoas com doenças reumáticas; ou de Silva et al. (2018a, 2018b), que atuaram na formação e capacitação de jovens trabalhadores da cultura e 
junto às pessoas em situação de rua com foco na construção e fortalecimento de redes, participação e cidadania, entre outras.

Macedo et al. (2016), na concretização da atividade de extensão proposta, partiram do entendimento de que esta pode - e deve - se inscrever para além do caráter assistencialista, exercendo um papel fundamental de comunicação entre universidade e sociedade. Nesta direção, Bardi et al. (2016) relatam que as oficinas culturais propostas para jovens que viviam em uma comunidade periférica foram percebidas como de interesse pela comunidade, uma vez que serviços públicos deste tipo eram inexistentes. Silva et al. (2019) relatam sobre transformaçôes no uso do espaço público de uma praça por jovens de um bairro na periferia e em vulnerabilidade social após a aproximação e vinculação destes com a equipe do projeto e proposta de realização desta com a comunidade local.

Macedo et al. (2016), com a atividade extensionista junto ao povo guarani, ao desvelarem questóes de etnicidade e interculturalidade, possibilitaram uma maior interação entre comunidade indígena e a universidade e especificamente rever as ações técnicas do terapeuta ocupacional junto a este grupo.

Della Barba et al. (2015), em atividade de extensão voltada à formação continuada de educadores de creches da rede municipal sobre promoção do desenvolvimento infantil, destacaram a importância da aproximação da universidade com a comunidade por meio da efetivação de açóes que empoderam os sujeitos envolvidos nos contextos da escola e da família.

Francelino \& Bregalda (2020), no projeto dedicado à formação de estudantes de terapia ocupacional para a atenção humanizada e sensível, identificaram a extensão universitária enquanto uma possibilidade de estratégia para transformação social, na qual o próprio estudante que faz parte do projeto constitui um agente de transformação.

Neste sentido, Coutinho et al. (2009) apontam que açôes oriundas da atividade de extensão favorecem a criação e implantação de políticas públicas que incluam o terapeuta ocupacional em suas diferentes formas de atuação.

\section{A extensão favorecendo o processo de ensino-aprendizagem}

Algumas publicações referiram que a atividade de extensão favoreceu o processo de ensino-aprendizagem tanto teórico como prático, sendo referida como um espaço potente para o aprendizado reflexivo, pautado em questóes da realidade do outro e que instigam o questionamento dos modos de pensar e fazer das pessoas envolvidas.

Sato et al. (2014) apontaram que a atividade de extensão consistia em uma estratégia de ensino para uma disciplina prática sobre geriatria e gerontologia de um curso de graduação em terapia ocupacional. Para Della Barba et al. (2017), a atividade de extensão promoveu a diversificação de cenários de ensino-aprendizagem.

Gomes et al. (2014) referiram que a extensão estimulou os estudantes a participarem de um processo de ensino-aprendizagem vivencial, que relacionava teoria com a prática e enfatizava a importância de uma formação pedagógica, humanística pautada numa visão social e preventiva, de forma que o profissional a ser formado consiga interagir com a comunidade e fornecer uma efetiva contribuição.

Neste sentido, Silva et al. (2015b) referem que o projeto de extensão possibilitou aos estudantes uma aula em campo real, desvelando e articulando conhecimentos da sala de 
aula para o terreno prático na temática. Para Silva et al. (2018b), a formação dos estudantes pela extensão possibilitou sensibilizá-los para as demandas sociais, fomentando uma visão crítica, de maneira a não pautarem suas açóes para a reprodução do status quo.

Joaquim et al. (2016) apontam que as estudantes do projeto de extensão vivenciaram o reconhecer-se como profissional de saúde, cujas açóes têm consequências tanto sobre o outro, o sujeito alvo da intervenção, como também sobre si mesmas, na medida em que a ação do outro repercute sobre nós e nos mobiliza a buscar modificaçóes em nosso próprio desempenho.

Joaquim et al. (2010) mencionam que, pela atividade envolver fundamentação teórica a ser adquirida com leituras e discussóes de textos e realização de uma ação prática, houve a possibilidade de refletir sobre o conhecimento teórico mediante a prática vivenciada, confrontando teorias com experiências e demandas do mundo real, sendo capaz de reorientar sua prática numa perspectiva de cuidado que respeita as diversidades e as singularidades existentes.

Dutra et al. (2018) relataram que os estudantes que participam de projetos de extensão tiveram a oportunidade de aprofundarem o conhecimento teórico a partir da experiência em um contexto real da prática e, além dos aprendizados teóricos e práticos adquiridos em um projeto de extensão, houve a oportunidade de conhecer e de se relacionar com pessoas de diferentes áreas, a partir de uma prática interdisciplinar.

Em conjunto, a extensão universitária também foi referida por Meneses et al. (2016), Galheigo \& Angeli (2008), Coutinho et al. (2009) e Francelino \& Bregalda (2020) como possibilidade de criação e/ou qualificação de campos de estágio, o que consequentemente possibilita a prestação de um serviço seja antes inexistente ou ampliando as possibilidades de cuidado, inclusive especializado e recursos oferecidos pela rede de assistência dos municípios envolvidos.

\section{Impacto na formaçáo discente}

Algumas publicações evidenciaram um impacto positivo da extensão na formação discente, sendo que a contribuição da extensão se deu no sentido de possibilitar o exercício do relacionar-se com pessoas, grupos e comunidades participantes ou protagonistas das intervenções e proposiçóes e/ou com outros profissionais, de colocar em prática a teoria vista em sala de aula e o desenvolvimento de um olhar crítico e sensível.

Della Barba et al. (2015) constataram a possibilidade de preparar o futuro profissional para atuar em equipes diversas e novos territórios para a terapia ocupacional, bem como a construção de novos modelos de cuidado.

Joaquim et al. (2016, p. 398) referem que, quanto à graduação em terapia ocupacional, por ter a duração de alguns anos e a atividade profissional permanecer por décadas, é imprescindível que a formação de um profissional tenha como foco "o aprender a conhecer, o aprender a fazer, o aprender a conviver e o aprender a ser, garantindo a integralidade $\mathrm{da}$ atenção à saúde com qualidade, eficiência e resolutividade".

Para Silva et al. (2015b), as vivências na prática extensionista possibilitaram aos estudantes a construção de uma postura profissional, o contato com visões específicas de outras áreas da saúde, o aprender a aprender e o discutir a promoção da saúde e o 
"empoderamento" dos sujeitos como promotores da sua saúde, possibilitando uma formação centrada na saúde e não na doença.

Dutra et al. (2018) referiram que a participação nos projetos de caráter socioeducativo e práticas sustentáveis colaborou para a formação dos estudantes enquanto agentes multiplicadores do processo de sensibilização da comunidade local quanto ao seu papel corresponsável nas açôes de proteção ambiental. Os próprios estudantes que participaram do projeto relatado por Dutra et al. (2018) indicaram que a extensão universitária permitiu a formação de um profissional cidadão, crítico, capaz de trabalhar de forma interdisciplinar, tendo a participação no projeto sido importante para o crescimento tanto profissional como pessoal.

Francelino \& Bregalda (2020) afirmam que o projeto de extensão proporcionou aos estudantes o aprimoramento da sensibilidade, o protagonismo no próprio processo de formação e o reconhecimento do papel enquanto agente de transformação social.

As atividades extensionistas também são qualificadas como espaços para a própria formação docente, docentes reconhecem que a trajetória profissional na qual está presente a realização da extensão subsidiou a própria formação, para suas habilidades enquanto docente e pesquisador.

Oliveira et al. (2003) relatam que a atividade de extensão trouxe benefícios tanto para as pessoas atendidas como para o crescimento profissional dos estudantes que compuseram a equipe de trabalho ao vivenciarem um campo de atuação considerado novo para a época e com demandas especificas da clientela oncológica.

\section{Discussáo}

As publicações trataram sobre atividade, projeto e/ou programa de extensão, tendo estes variados objetivos, participantes, locais e açôes promovidas pela terapia ocupacional. Nenhuma outra revisão sobre a temática terapia ocupacional e atividade de extensão foi encontrada para que estes resultados pudessem ser comparados.

Entretanto, alguns estudos apresentaram temas reincidentes que propiciaram a criação das categorias temáticas sobre a indissociabilidade com o ensino e a pesquisa, relaçáo da universidade com a comunidade, processo de ensinoaprendizagem e formação discente, passíveis de discussão com a literatura existente.

Sobre a indissociabilidade, é importante historiar que a extensão universitária não foi pensada e realizada sob este princípio, sendo que sua primeira referência legal no Brasil ocorreu pelo Decreto no 19.851 que referia que o objetivo era elevar o nível de cultura geral do povo através de cursos, conferências e demonstrações práticas, o que resultou em atividades que beneficiavam apenas a classe que já tinha acesso ao ensino superior (Brasil, 1931). Em 1961, mesmo com a promulgação da Lei no 4.024, mantém-se a prática extensionista voltada para aqueles que tivessem concluído o ciclo colegial (termo utilizado na época) ou que possuíam a graduação, podendo com isso concretizarem cursos de capacitaçáo, especialização e/ou aprimoramento profissional (Brasil, 1961).

Entretanto, de 1960 a 1964, tem-se o registro do início de ocorrência de atividade extensionista desvinculada da Universidade e promovida pela União Nacional dos 
Estudantes (UNE) que defendia a atuação do estudante na realidade social das comunidades e a troca de experiências entre os participantes. No entanto, este tipo de atividade de extensão foi impedido durante o regime militar sob o julgo de que náo compreendia uma atuaçáo estudantil em consonância com o ideal de "desenvolvimento e segurança” do período. Em adição, o governo da época coloca em prática dois projetos: um denominado Programa Centro Rural Universitário de Treinamento e Ação Comunitária (CRUTAC) e o outro Projeto Rondon instituído em nível nacional pelo Decreto-Lei n. ${ }^{\circ} 67.505$ (Leite \& Nunes, 2009).

Em 1968, foi promulgada a Lei no 5.540/68, a Lei Básica da Reforma Universitária, que passa a reconhecer a indissociabilidade entre o ensino e a pesquisa, apesar de ainda possuir as influências norteadoras do início do século que determina a realização de cursos (origem europeia) e da prestação de serviços (vertente americana).

De acordo com Nogueira (2001), a extensão universitária como promoção de cursos ou prestação de serviços se torna restrita a um nível que a impede de alcançar sua dimensão acadêmica. Dificilmente, nessas atividades, realizadas de forma isolada, existe articulação com as demais atividades acadêmicas - o ensino e a pesquisa. Ademais, quando realizadas desvinculadas de um planejamento institucional, muitas vezes atendem a uma única clientela oriunda de camada social que pode pagar por estes serviços e que, em geral já tem acesso ao ensino superior.

Apenas em 1975 as atividades extensionistas começaram a receber um novo modelo conceitual a partir da elaboração, pelo Ministério da Educação e Cultura, do Plano de Trabalho da Extensão Universitária que preconizava a extensão enquanto forma da Instituição de Ensino Superior estender seu atendimento a organizações, outras instituiçóes e populaçóes de um modo geral, possibilitando que o ensino e a pesquisa fossem acessíveis a estes.

Nessa nova concepçáo, a extensão universitária deixa de ser uma ferramenta que atende apenas uma parcela da sociedade e passa a proporcionar a troca entre os saberes acadêmicos e os saberes populares. Além disso, também insere a participação docente antes renegada (Nogueira, 2001).

A Resolução No 7, de 18 de Dezembro de 2018, é a legislação brasileira vigente mais atual que estabelece as diretrizes para a extensão na educação superior brasileira, no Art. $3^{\circ}$, a extensão universitária é considerada como "atividade que se integra à matriz curricular e à organização da pesquisa, constituindo-se em processo interdisciplinar, político educacional, cultural, científico, tecnológico, que promove a interação transformadora entre as instituiçóes de ensino superior e os outros setores da sociedade" (Brasil, 2018).

Assim, as diferentes propostas extensionistas devem ser consideradas de forma indissociável com o ensino e a pesquisa, aliada à participação da comunidade e necessariamente transformadora, gerando debates e produzindo saberes coletivamente para todos os envolvidos.

Pivetta et al. (2010) salientam que o princípio da indissociabilidade entre ensino, pesquisa e extensão reflete um conceito de qualidade do desempenho acadêmico capaz de favorecer a autorreflexão crítica, a emancipação teórico-prática e o significado de responsabilidade social proporcionado pela aproximaçáo entre a universidade e comunidade. 
O ensino, a pesquisa e a extensão, enquanto atividades complementares e interdependentes, precisam ter valoraçóes equivalentes no sistema universitário, sob o risco de desenvolver conhecimento cindido e reducionista. A qualidade e o sucesso dos profissionais formados pelas universidades dependem, em grande parte, do nível de interação e articulação entre os três pilares do conhecimento (ensino-pesquisa-extensão) (Fórum de Pró-Reitores de Extensão das Universidades Públicas Brasileiras, 2006).

Contudo, com as novas diretrizes que regem a extensão (Brasil, 2018), a exigência é de articulação e não de indissociabilidade, o que promove aberturas para outras formas de conceber as atividades. Percebe-se, portanto, que o uso do termo articulação não representa obrigatoriedade e amplia a disputa discursiva sobre os sentidos e usos da extensão.

A respeito da relação da universidade com a comunidade, em continuidade às mudanças referidas acima, em novembro de 1987, foi criado o Fórum Nacional de Pró-Reitores de Extensão das Universidades Brasileiras que, desde então, tem buscado fomentar o avanço nas reflexôes e compreensão sobre a extensão universitária. A concepção fomentada por este fórum é baseada na concepção de que universidade deve participar e/ou fomentar açôes que visem à superação das condições de desigualdade e exclusão existentes no Brasil. Neste sentido, a extensão universitária assume o papel de promotora da relação entre Universidade e setores da sociedade (Fórum de Pró-Reitores de Extensão das Universidades Públicas Brasileiras, 2012).

Para Nunes \& Silva (2011), a extensão universitária funciona como uma via de máo dupla, possibilitando que a comunidade a qual recebe os serviços prestados pela universidade aprende e a universidade aprende com os saberes populares desta comunidade. Assim, há uma troca de conhecimentos, cada qual com suas particularidades, mas sem desconsiderar nenhum.

Pivetta et al. (2010) referem que as práticas extensionistas resultam também na produção de novas tecnologias de cuidado em saúde e em outras áreas, assim como de um processo de ensino-aprendizagem reflexivo, ético, dinâmico e em interação com a realidade micro e macrossocial.

Nesta direção, o processo de ensino-aprendizagem propiciado pela atividade de extensão ocorre por meio de um saber que é construído de forma dialogada entre docente, discente e aplicabilidade de teorias e pressupostos.

Segundo Oka (2014), a construção do saber no projeto de extensão possui a característica de ser o tempo todo dialogado, pois é considerado o meio como se transmite o conteúdo, colocando o aprendiz no processo, ou seja, a construção do saber acontece com o graduando e não para o graduando. Através das conversas e discussôes, são detectados os problemas e assim poderão ser encontrados meios para intervir naquela situação, ancorados nos conhecimentos adquiridos por meio da leitura, compartilhamento e reconstrução do mundo, impregnando de significados o conteúdo teórico adquirido durante a graduação.

Assim, a atividade de extensão é promotora de conhecimentos e isso se dá pelo mecanismo da experiência, ou seja, quando os discentes póem em prática a teoria recebida em sala de aula, quando aprimoram suas habilidades de comunicação e 
expressão e, principalmente, quando desenvolvem habilidades para tomadas de decisão frente a diversos aspectos da futura área de atuação (Lima et al., 2017).

Em adição, Nogueira (2001) refere que a extensão universitária fornece subsídios para o aprimoramento curricular do discente e para a criação de novos cursos e campos de estágio.

Portanto, a atividade de extensão constitui uma ferramenta pedagógica positiva para a formação discente.

Figueiredo et al. (2020), Paterra \& Figueiredo (2018) e Paterra et al. (2015), em pesquisas sobre as atividades de extensão elaboradas e concretizadas pelos docentes do Departamento de Terapia Ocupacional da UFSCar, obtiveram dentre os resultados que a atividade de extensão possibilita que os discentes entrem em contato com as diferentes demandas das diversas pessoas, grupos e comunidades e contextos múltiplos. Além disso, conhecem, testam, constroem ferramentas, protocolos e confecção de recursos na tentativa de atendimento a estas demandas. A partir da participação dos discentes nas atividades de extensão, são despertadas perguntas que levam ao pensamento investigativo, culminando na produçáo dos próprios Trabalhos de Conclusão de Curso e Iniciaçóes Científicas oriundas dessas experiências.

Para o discente extensionista, não existe apenas um projeto de extensão e sim vários que poderão participar de acordo com seus interesses e disponibilidade de horário. Oka (2014) defende que cada um tem seus motivos para participar das atividades: seja a troca de experiências, a mudança de seu mundo e oferecer sua contribuição para modificar e melhorar o mundo do outro, crescer como pessoa, como profissional, desenvolver habilidades para o trabalho em equipe, promover a saúde e prevenção de agravos. A extensão proporciona a integraçáo entre o conhecimento popular e o conhecimento científico o que propicia presumir a futura atuação profissional.

Por fim, Paterra \& Figueiredo (2018) referem que os discentes do curso de Terapia Ocupacional da UFSCar anualmente têm a oportunidade de realizar atividades de extensão de diferentes tipos e com distintos objetivos. De 2000 até 2017, foram ofertadas 409 atividades de extensão, sendo que 354 foram do tipo assistência e dirigidas à comunidade, 52 eventos acadêmicos como, por exemplo, semanas de estudos, seminarios, simposios, cursos, entre outros, 7 Atividades Curriculares de Integração Ensino, Pesquisa e Extensão (ACIEPE) ${ }^{1}$ e 5 foram relativas à publicação dos Cadernos Brasileiros de Terapia Ocupacional.

Com isso, há um incremento na formação discente, possibilitando diversas experiências, desde as de cunho científico até o contato com a realidade e demandas sociais, ambas favorecendo uma formação discente pautada na reflexão, na disseminação e atualização do conhecimento e no comprometimento com uma sociedade menos injusta (Figueiredo et al., 2020).

\footnotetext{
${ }^{1}$ A ACIEPEs constituem atividades curriculares complementares às obrigatórias contidas no curriculum de cada curso de graduaçấo. Possuem duração semestral de 60 horas e os discentes tem liberdade para realizarem ou não e escolherem qual desejam realizar. Esta modalidade de extensão universitária representa a integração entre ensino, pesquisa e extensão sendo que a carga horária cumprida é revertida em créditos curriculares.
} 


\section{Conclusão}

Com base nos resultados encontrados, evidenciou-se a realização da extensão universitária de forma indissociável com o ensino e pesquisa, favorecendo a articulação entre a universidade e a sociedade na formação em terapia ocupacional. Em conjunto, as atividades de extensão têm se caracterizado por uma prática acadêmica articulada às demandas sociais, favorecedora do diálogo entre a Universidade e a Sociedade, da assistência à(s) comunidade(s) e da democratização do saber acadêmico. Ressalta-se que a grande concentração de atividades extensionistas são realizadas pelas universidades públicas que possuem estratégias para articular ensino, pesquisa e extensão distintas da maioria das Instituiçóes de Ensino Superior privadas, que se ausentam desta função e responsabilidade.

Foi possível verificar que as atividades extensionistas desenvolvidas pelos docentes terapeutas ocupacionais estiveram voltadas para a produção de práticas, saberes e fazeres que respondam aos complexos problemas sociais. O reflexo desta produção esteve presente na diversidade encontrada em relação aos diferentes sujeitos, grupos, comunidades e/ou populaçóes. Foram identificados todos os cursos de vida. As atividades extensionistas foram realizadas em espaços plurais, desde a própria universidade, como serviços, projetos, centros e na própria comunidade, nos quais foram identificados os setores da saúde, educação, assistência social e cultura. Assim, reconhecemos que a potência do trabalho está associada às possibilidades e autonomia $\mathrm{e}$ democratização docente e universitária em poder promover atividades extensionistas tão diversas, e demonstra o incrível potencial que a terapia ocupacional tem desenvolvido na integração entre ensino-pesquisa-extensão.

Além disso, a concretização de atividades extensionistas tem impactado positivamente no processo de ensino e aprendizagem, especialmente na terapia ocupacional, transformado a carreira docente e propiciado uma formação discente crítica, reflexiva e cidadâ, por meio do contato direto com comunidades que incitam açôes de resolutividade e suas demandas, gerando e atualizando práticas, técnicas, reflexóes e vivências.

Por fim, o número de publicações encontradas representa apenas 3,4\% de todas as publicaçôes contidas nos três periódicos analisados, o que sugere a necessidade de novos estudos e publicaçóes relacionados à extensão universitária em terapia ocupacional.

Da mesma forma, a comunidade universitária está em constante embate a respeito das diferentes forças e atravessamentos políticos, econômicos, culturais e ideológicos, dimensôes que atravessam e definem as posiçôes sobre questôes presentes. Algumas delas são a inserção das atividades extensionistas nos currículos da graduação, a relação e a disputa entre público-privado, a dificuldade de financiamento público e a necessidade de manter e ampliar as conquistas alcançadas com a expansão das universidades. Além disso, mencionam-se os desafios de desconstrução histórico da elitização, colonização, colonialidade e restrição universitária, recuperação e restauração histórica de grupos excluídos deste espaço, entre outros. Enfrentamentos esses associados às demandas sociais que devem compor a formação consciente de futuros profissionais.

Além de enfrentamento de questóes como o avanço da tecnologia e a interferência em todas as instâncias da vida, a extinção de inúmeros postos de trabalho, o enxugamento dos serviços públicos, as urgências em relação às questóes ambientais, as constantes crises, 
inclusive sanitárias, pandêmicas, entre outros demandam formaçóes cada vez ainda mais com habilidades sociais e humanas, com capacidade de resolução de problemas e conflitos, pensamento crítico para responder problemas socais reais e urgentes. Assim, temos que encontrar novas e urgentes saídas das quais certamente as atividades extensionistas serão imprescindíveis.

Afinal, a extensão, além de função própria da universidade, incorpora uma gama de atividades que podem ser utilizadas para o aprimoramento de conhecimentos teóricos e práticos associados aos problemas e demandas reais de pessoas, grupos e comunidades com as quais o terapeuta ocupacional trabalha e, ainda, potencializar, promover e ampliar o escopo das práticas e dos campos de saberes e fazeres plurais conscientes da responsabilidade e do compromisso ético político junto às pessoas, grupos e comunidades.

\section{Referências}

Almeida, M. C., Soares, C. R. S., Barbosa, A. T. S., Kazanji, D. P., Lima, S. L., \& Prado, P. (2015). Novos olhares para a juventude: descobrindo caminhos. Cadernos de Terapia Ocupacional da UFSCar, 23(4), 863870. http://dx.doi.org/10.4322/0104-4931.ctoER0672.

Almeida, M. M. (2004). O jornal e o vídeo como meio de expressão de jovens internados na Unidade Educacional da FEBEM de Ribeirão Preto. Revista de Terapia Ocupacional da Universidade de São Paulo, 15(1), 33-38.

Alves, A. L., Cavalcanti, A., Castro, S. S., Andrade, V. S., \& Nunes, C. M. P. (2012). Perfil sócio demográfico e de funcionalidade/ incapacidade de pessoas atendidas em um programa de reabilitação da máo. Revista de Terapia Ocupacional da Universidade de Säo Paulo, 23(1), 62-71.

Angeli, A. A. C., \& Fonseca, T. M. G. (2015). O Menino-Cachorro e o projeto TOCCA: intensidades e experimentaçôes na constituição de açôes em Terapia Ocupacional. Cadernos de Terapia Ocupacional da UFSCar, 23(4), 815-828.

Angelli, A. A. C., Castro, E. D., Lima, E. M. F. A., \& Inforsato, E. (2009). A. Pacto: 10 anos de encontros, pesquisas e produção na interface das artes e da saúde. Revista de Terapia Ocupacional da Universidade de São Paul, 20(3), i-i. https://doi.org/10.11606/issn.2238-6149.v20i3pi-i.

Arksey, H., \& O’Malley, L. (2005). Scoping studies: towards a methodological framework. International Journal of Social Research Methodology, 8(1), 19-32.

Baldani, A. C., \& Castro, E. D. (2007). Construindo espaços de habitar: açóes de terapia ocupacional com uma criança em situação de risco social. Revista de Terapia Ocupacional da Universidade de São Paulo, 18(1), 1-10.

Bardi, G., Monzeli, G. A., Macedo, M. D. C., Neves, A. T. L., \& Lopes, J. S. R. (2016). Oficinas socioculturais com crianças e jovens sob a perspectiva da Terapia Ocupacional Social. Cadernos de Terapia Ocupacional da UFSCar, 24(4), 811-819. http://dx.doi.org/10.4322/0104-4931.ctoRE0643.

Brasil. (1931, 11 de abril). Decreto no 19.851, de 11 de abril de 1931. Dispóe que o ensino superior no Brasil obedecerá, de preferencia, ao systema universitario, podendo ainda ser ministrado em institutos isolados, e que a organização technica e administrativa das universidades é instituida no presente Decreto, regendo-se os institutos isolados pelos respectivos regulamentos, observados os dispositivos do seguinte Estatuto das Universidades Brasileiras. Diário Oficial [da] República Federativa do Brasil, Brasília, seção 1, p. 5800. Recuperado em 01 de setembro de 2020, de https://www2.camara.leg.br/legin/fed/decret/19301939/decreto-19851-11-abril-1931-505837-publicacaooriginal-1-pe.html

Brasil. (1961, 20 de dezembro). Lei no 4.024, de 20 de Dezembro de 1961. Fixa as Diretrizes e Bases da Educaçáo Nacional. Diário Oficial [da] República Federativa do Brasil, Brasília. Recuperado em 1 de setembro de 2020, de http://www.planalto.gov.br/ccivil_03/LEIS/L4024.htm

Brasil. (1996, 20 de dezembro). Decreto no. 9.394, de 20 de dezembro de 1996. Estabelece as diretrizes e bases da educação nacional. Diário Oficial [da] República Federativa do Brasil, Brasília. Recuperado em 20 de julho de 2020, de http://www.planalto.gov.br/ccivil_03/Leis/L9394.htm 
Brasil. (2018, 18 de dezembro). Resolução no 7, de 18 de dezembro de 2018. Estabelece as Diretrizes para a Extensão na Educação Superior Brasileira e regimenta o disposto na Meta 12.7 da Lei no 13.005/2014, que aprova do Plano Nacional da Educação - PNE 2014-2024 e dá providências. Diário Oficial [da] República Federativa do Brasil, Brasília, seçáo 1, p. 49. Recuperado em 10 de setembro de 2020, de http://portal.mec.gov.br/index.php?option=com_docman\&view=download\&alias=104251-rces00718\&category_slug=dezembro-2018-pdf\&Itemid=30192

Carbonari, M. E. E., \& Pereira, A. C. (2007). A extensão universitária no Brasil, do assistencialismo à sustentabilidade. Review of Education, 10(10), 23-28.

Carrasco, B. G. (2005). Retrato de uma creche: possibilidades da atuação da Terapia Ocupacional na educação infantil (0-2 anos). Cadernos de Terapia Ocupacional da UFSCar, 13(2), 117-121.

Castro, E. D., Saito, C. M., Drumond, F. V. F., \& Lima, L. J. C. (2011). Ateliês de Corpo e Arte: inventividade, produção estética e participação sociocultural. Revista de Terapia Ocupacional da Universidade de São Paulo, 22(3), 254-262.

Colquhoun, H. L., Levac, D., O’Brien, K. K., Straus, S., Tricco, A. C., Perrier, L., Kastner, M., \& Moher, D. (2014). Scoping reviews: time for clarity in definition, methods, and reporting. Journal of Clinical Epidemiology, 67(12), 1291-1294.

Correa, G. C., \& Santana, V. C. (2014). Avalição do impacto de uma avalição de terapia ocupacional com ênfase no desempenho ocupacional de crianças e adolescentes com deficiência visual. Revista de Terapia Ocupacional da Universidade de Säo Paulo, 25(1), 43-50.

Correia, R., \& Akerman, M. (2015). Desenvolvimento local participativo, rede social de suporte e ocupação humana: relato de experiência em projeto de extensão. Revista de Terapia Ocupacional da Universidade de São Paulo, 26(1), 159-165.

Costa, C. R., Souza, S. T., Gontijo, G. P., Simoes, G. R., Fonseca, P. S., \& Bortolus, M. V. (2015). Tecnologias sonos terapêuticas. Revista de Terapia Ocupacional da Universidade de São Paulo, 26(1), 153-158.

Coutinho, S., Castro, E. D., Inforsato, E. A., Lima, L. J. C., Galvanese, A. T., Asanuma, G., \& Lima, E. M. F. A. (2009). Açóes de Terapia Ocupacional no território da cultura: a experiência de cooperação entre o Museu de Arte Contemporânea da USP (MAC USP) e o Laboratório de Estudos e Pesquisas Arte e Corpo em Terapia Ocupacional. Revista de Terapia Ocupacional da Universidade de São Paulo, 20(3), 188-192.

Della Barba, P. C. S., \& Minatel, M. M. (2013). Contribuiçóes da Terapia Ocupacional para a inclusão escolar de crianças com autismo. Cadernos de Terapia Ocupacional da UFSCar, 21(3), 601-608. http://dx.doi.org/10.4322/cto.2013.062.

Della Barba, P. C. S., Gonçalves, A., Aniceto, B., Rizzo, I. C., Crippa, J. N., Lourenço, M. C., Santos, N. A., Nishiama, T. T., Joia, A. F., Pinheiro, R. C., Marini, B. P. R., Martinez, C. M. S., \& Joaquim, R. H. V. T. (2015). Avaliação de atividade de ensino, pesquisa e extensão em vigilância do desenvolvimento infantil: a perspectiva de graduandos em terapia ocupacional. Revista de Terapia Ocupacional da Universidade de Säo Paulo, 26(2), 274-280.

Della Barba, P. C. S., Barros, V. M., Marques, E. A., Farias, A. Z., Aniceto, B., \& Miyhamoto, E. R. (2017). A Terapia Ocupacional em um processo de capacitaçáo sobre vigilância do desenvolvimento infantil na atenção básica em saúde. Cadernos de Terapia Ocupacional da UFSCar, 25(1), 223-233. http://dx.doi.org/10.4322/0104-4931.ctoRE0747.

DePoy, E., \& Gitlin, L. (2011). Mixed Method Designs. In E. DePoy \& L. Gitlin (Eds.), Introduction to Research: Understanding and Applying Multiple Strategies (pp.173-178). St Louis: Mosby.

Dutra, F. C. M. S., Roberto, W. M., Coelho, B. L., \& Almeida, R. (2018). Envolvimento em ocupaçôes sustentáveis: mudanças nos hábitos de vida a partir de espaços de práticas educativas. Cadernos de Terapia Ocupacional, 26(2), 345-355. http://dx.doi.org/10.4322/2526-8910.ctoAO1143.

Emmel, M. L. G. (2010). Desafios da docência em terapia ocupacional. In Anais do $12^{\circ}$ Encontro Nacional de docentes de Terapia Ocupacional. Curitiba: UFPR.

Figueiredo, M. O., Paterra, I. P., Silva, C. R., \& Cardinalli, I. (2020). Contribución de las actividades de extensión a la formación en Terapia Ocupacional. Revista Ocupación Humana, 20(1), 7-26. 
Fórum de Pró-Reitores de Extensão das Universidades Públicas Brasileiras - FORPROEX. (2006). Indissociabilidade Ensino-Pesquisa-Extensão e a Flexibilização Curricular: uma visão da Extensão. Porto Alegre: UFRGS.

Fórum de Pró-Reitores de Extensão das Universidades Públicas Brasileiras - FORPROEX. (2012). Politica Nacional de Extensão Universitária. Manaus: MEC/SeSU.

Francelino, V. C. S., \& Bregalda, M. M. (2020). Poesia, arte e sensibilidade: contribuiçóes de um projeto de extensão para a formação de estudantes de terapia ocupacional. Cadernos Brasileiros de Terapia Ocupacional, 28(1), 50-73. http://dx.doi.org/10.4322/2526-8910.ctoAO1820.

Freire, P. (1977). Extensão e comunicação? Rio de Janeiro: Paz e Terra.

Galheigo, S. M., \& Angeli, A. A. C. (2008). Terapia Ocupacional e o cuidado integral a saúde de crianças e adolescentes: a construçáo do Projeto ACCALANTO. Revista de Terapia Ocupacional da Universidade de São Paulo, 19(3), 137-143.

Garcia, N. R., Pfeifer, L. I., \& Panúncio-Pinto, M. P. (2012). As caixas de histórias na visão de profissionais de saúde como estratégia de enfrentamento da hospitalização infantil. Revista de Terapia Ocupacional da Universidade de São Paulo, 23(2), 169-177.

Gomes, C., Coutinho, G., \& Miyamoto, S. (2014). Efeitos do programa de educação em pacientes com artrite reumatóide do Serviço de Reumatologia do Hospital Universitário Cassiano Antonio de Moraes (HUCAM) - Projeto Piloto. Revista de Terapia Ocupacional da Universidade de São Paulo, 24(3), 250-258.

Joaquim, R. H. V. T., Alburquerque, I., Cunha, T. T., Paez, L., \& Takeda, B. (2010). A proposta e a implantaçáo de um projeto de extensão: resgate do cotidiano de jogos e brincadeiras em uma enfermaria pediátrica. Revista de Terapia Ocupacional da Universidade de São Paulo, 18(2), 191-198.

Joaquim, R. H. V. T., El Khatib, U., \& Della Barba, P. C. S. (2016). A integração do processo ensino e aprendizagem de alunas de Terapia Ocupacional e o cuidado de mães de bebês de risco na hospitalização. Cadernos de Terapia Ocupacional da UFSCar, 24(2), 397-402. http://dx.doi.org/10.4322/01044931.ctoRE0729.

Joaquim, R. H. V. T., Silvestrini, M. S., \& Marini, B. P. R. (2014). Grupo de mães de bebês prematuros hospitalizados: experiência de intervençáo de Terapia Ocupacional no contexto hospitalar. Cadernos de Terapia Ocupacional da UFSCar, 22(1), 145-150. http://dx.doi.org/10.4322/cto.2014.016.

Justa, F. M. C., \& Holanda, I. C. L. C. (2012). Teatro com adolescentes em risco social: práticas de promoção da saúde no contexto terapêutico ocupacional. Revista de Terapia Ocupacional da Universidade de São Paulo, 23(1), 16-23.

Leite, M. T. F., \& Nunes, B. M. V. T. (2009). Centro Rural Universitário de Treinamento e Ação Comunitária - um resgate histórico 1975-1986. Texto \& Contexto Enfermagem, 18(3), 427-435.

Lima, J. E. C., Silva, I. R. N., Neto, P. F. N., Pereira, C. K. S., \& Bakke, L. A. (2017). A importância da extensão universitária na formaçáo profissional: experiência vivenciada por alunos do curso de farmácia. In Anais do $2^{\circ}$ Congresso Brasileiro de Ciências da Saúde (II CONBRACIS). Campina Grande: Universidade Estadual da Paraíba. Recuperado em 18 de novembro de 2020, de https://editorarealize.com.br/artigo/visualizar/28957

Lima, L. J. C., \& Silveira, N. D. R. (2009). Visóes sobre o envelhecer: o distanciamento e a proximidade da velhice com a grande cidade. Revista de Terapia Ocupacional da Universidade de São Paulo, 20(3), 171-179.

Lima, R. C., Silva, T. N. R., Alves, G. B. O., Sampaio, R. F., Fonseca, J. G. M., Lacerda, L. L., \& Pinheiro, T. M. M. (2016). Programa de Atenção Integral à Saúde do Artista de Performance: relato da experiência desenvolvida em um serviço universitário em Minas Gerais. Revista de Terapia Ocupacional da Universidade de São Paulo, 27(2), 221-227.

Lorezon, M. R., \& Marquetti, F. C. (2016). Oficina de Ação: uma estratégia de intervenção grupal em Terapia Ocupacional no Campo da Saúde Mental. Revista de Terapia Ocupacional da Universidade de São Paulo, $27(3), 342-348$.

Luiz, C. C. A., \& Macedo, M. D. C. D. (2013). Natação e atividades aquáticas para populaçôes especiais: uma experiência em terapia ocupacional. Cadernos de Terapia Ocupacional da UFSCar, 11(2), 124-127. 
Macedo, M. D. C., Neves, A. T. L., Bardi, G., Monzeli, G. A., \& Mota, V. V. (2016). Olhares em formação: refletindo a prática da terapia ocupacional em um contexto cultural a partir de experiências com povos indígenas. Cadernos de Terapia Ocupacional da UFSCar, 24(1), 77-89. http://dx.doi.org/10.4322/01044931.ctoAO0665.

Meneses, K. V. P., Garcia, P. A., Abreu, C. B. B., \& Paulin, G. T. (2016). TO Clicando - inclusão social e digital de idosos. Cadernos de Terapia Ocupacional da UFSCar, 24(3), 621-628. http://dx.doi.org/10.4322/0104-4931.ctoRE0639.

Monteiro, R. J. S., Gontijo, D. T., Facundes, V. L. D., \& Vasconcelos, A. C. S. (2015). "Pensando como um menino é mais fácil": construçôes sobre as relaçóes de gênero no discurso de meninas adolescentes. Revista de Terapia Ocupacional da Universidade de São Paulo, 26(2), 207-215.

Nascimento, D. M., \& Souza, C. F. L. S. (2017). Política Nacional de Extensão Universitária: análise da experiência do Instituto de Ciências da Saúde da UFPA. Extensio: Revista Eletrônica de Extensão, 14(26), 23-44. http://dx.doi.org/10.5007/1807-0221.2017v14n26p23.

Nogueira, M. D. P. (2001). Extensão universitária no Brasil: uma revisão conceitual. In D. S. Faria (Org.), Construção conceitual da extensão universitária na América Latina (pp. 57-72). Brasília: UNB.

Noordhoek, J., Silva, M. C. O., Torquetti, A., \& Cisneros, L. L. (2009). Relato de experiência da atuação da terapia ocupacional em grupo de indivíduos reumáticos. Revista de Terapia Ocupacional da Universidade de São Paulo, 20(1), 13-19.

Nunes, A. L. P. F., \& Silva, M. B. C. (2011). A extensão universitária no ensino superior e a sociedade. MalEstar e Sociedade, 4(7), 119-133.

O’Brien, K. K., Colquhoun, H., Levac, D., Baxter, L., Tricco, A. C., Straus, S., Wickerson, L., Nayar, A., Moher, D., \& O’Malley, L. (2016). Advancing scoping study methodology: a web-based survey and consultation of perceptions on terminology, definition and methodological steps. BMC Health Services Research, 26(16), 305.

Oka, S. S. (2014). A importância do saber cuidar no processo de formação do graduando em enfermagem. In A. C. M. Silva, A. C. P. Bretas \& C. L. A. Santana (Orgs.), Com-Unidade: experiências extensionistas (pp. 4248). Sáo Paulo: Páginas \& Letras Editora e Gráfica.

Oliveira, A. S., Silva, A. A., Albuquerque, I., \& Akashi, L. T. (2003). Reflexões sobre a prática de terapia ocupacional em oncologia na cidade de São Carlos. Cadernos de Terapia Ocupacional da UFSCar, 11(2), 118-123.

Oliver, F. C., Aoki, M., Tissi, M. C., \& Nicolau, S. M. (2003). Reabilitação com ênfase no território - Jardim D’Abril e Jardim Boa Vista, no município de São Paulo. Revista de Terapia Ocupacional da Universidade de São Paulo, 14(3), 141-146.

Paterra, I. P., \& Figueiredo, M. O. (2018). Extensão universitária em terapia ocupacional na Universidade Federal de São Carlos. In Anales da 26 Jornadas de Jóvenes Investigadores AUGM. A 100 años de la reforma universitária: saber te hace libre. Argentina: Universidad Nacional de Cuyo.

Paterra, I. P., Figueiredo, M. O., \& Silva, C. R. (2015). Caracterização das atividades de extensão implementadas por docentes do curso de terapia ocupacional da UFSCar. In Anais $2^{\circ}$ Congresso de Extensão da Associação das Universidades do Grupo de Montevidéu (AUGM). Extensão e Sociedade: A Indissociabilidade entre Ensino, Pesquisa e Extensão (pp. 157-158). Campinas: UNICAMP.

Paula, J. A. (2013). A extensão universitária: história, conceito e propostas. Interfaces - Revista de Extensão da $U F M G, 1(1), 5-23$.

Peruzzolo, D. L., Oliveira, L. D., Filheiro, M., \& Souza, A. P. R. (2015). Contribuiçôes à clínica da Terapia Ocupacional na área da intervenção precoce em equipe interdisciplinar. Cadernos de Terapia Ocupacional da UFSCar, 23(2), 295-303. http://dx.doi.org/10.4322/0104-4931.ctoAO0515.

Peters, M. D., Godfrey, C. M., Khalil, H., McInerney, P., Parker, D., \& Soares, C. B. (2015). Guidance for conducting systematic scoping reviews. International Journal of Evidence-Based Healthcare, 13(3), 141-146.

Pivetta, H. M. F., Backes, D. S., Carpes, A., Battistel, A. L. H. T., \& Marchiori, M. (2010). Ensino, pesquisa e extensão universitária: em busca de uma integração efetiva. Linhas Críticas, 16(31), 377-390.

Santos, B. S., \& Filho, N. A. (2008). A Universidade no Século XXI: para uma universidade nova. Coimbra: Almedina. 
Sato, A. T., Batista, M. P. P., \& Almeida, M. H. M. (2014). "Programas de estimulação da memória e funções cognitivas relacionas": opinióes e comportamentos dos idosos participantes. Revista de Terapia Ocupacional da Universidade de São Paulo, 25(1), 51-59.

Silva, V. T. B. L., Silva, A. L. F., Muguba, M. C., Lamboglia, C. M. G. F., \& Silva, C. A. B. (2015a). Terapia Ocupacional e pessoas com sobrepeso e obesidade: conhecimentos e partilhas. Cadernos de Terapia Ocupacional da UFSCar, 23(1), 211-219. http://dx.doi.org/10.4322/0104-4931.ctoRE418.

Silva, C. R., Cardinalli, I., \& Lopes, R. E. (2015b). A utilização do blog e de recursos midiáticos na ampliação das formas de comunicaçáo e participação social. Cadernos de Terapia Ocupacional da UFSCar, 23(1), 131142. http://dx.doi.org/10.4322/0104-4931.ctoAO513.

Silva, C., Silvestrini, M., Prado, A. C. A., Vasconcelos, D., Farias, A., \& Mancini, M. A. (2018a). Economia criativa na relação entre trabalho e cultura para a juventude. Revista de Terapia Ocupacional da Universidade de São Paulo, 29(2), 120-128.

Silva, C. R., Silvestrini, M. S., Von Poellnitz, J. C., Prado, A. C. S. A., \& Leite Junior, J. D. (2018b). Estratégias criativas e a população em situação de rua: terapia ocupacional, arte, cultura e deslocamentos sensíveis. Cadernos Brasileiros de Terapia Ocupacional, 26(2), 489-500. http://dx.doi.org/10.4322/2526-8910.ctoRE1128.

Silva, M. J., Oliveira, M. L., \& Malfitano, A. P. S. (2019). O uso do espaço público da praça: considerações sobre a atuaçáo do terapeuta ocupacional social. Cadernos Brasileiros de Terapia Ocupacional, 27(2), 438447. http://dx.doi.org/10.4322/2526-8910.ctoRE1746.

Tricco, A. C., Lillie, E., Zarin, W., O’Brien, K., Colquhoun, H., Kastner, M., Levac, D., Ng, C., Sharpe, J. P., Wilson, K., Kenny, M., Warren, R., Wilson, C., Stelfox, H. T., \& Straus, S. E. (2016). A scoping review on the conduct and reporting of scoping reviews. BMC Medical Research Methodology, 16(15), 1-10. http://dx.doi.org/10.1186/s12874-016-0116-4.

Zanni, K. P. (2005). A intervenção da terapia ocupacional com paciente autista no setting aquático. Cadernos de Terapia Ocupacional da UFSCar, 13(2), 123-127.

\section{Contribuiçáo dos Autores}

Mirela de Oliveira Figueiredo foi responsável pela orientação do trabalho e pelas análises realizadas. Renata Batistão e Roberta Giampá Roiz realizaram a revisão de literatura e parte das análises dos dados. Carla Regina Silva e Claudia Maria Simóes Martinez produziram novas análises e fizeram contribuiçóes ao texto para a produçáo do manuscrito. Todas as autoras são responsáveis pela redação e revisão do manuscrito e aprovaram a versão final do texto.

\section{Fonte de Financiamento}

CNPq - PIBIC - UFSCar. (Conselho Nacional de Desenvolvimento Científico e Tecnológico - Programa Interno de Iniciação Científica - Universidade Federal de São Carlos).

\section{Autor para correspondência}

Mirela de Oliveira Figueiredo

e-mail: mirelafigueiredo@gmail.com

\section{Editora de seçáo}

Profa. Dra. Daniela Tavares Gontijo 